\title{
Image-based surface reconstruction in geomorphometry - merits, limits and developments
}

\author{
Anette Eltner ${ }^{1}$, Andreas Kaiser ${ }^{2}$, Carlos Castillo ${ }^{3}$, Gilles Rock ${ }^{4}$, Fabian Neugirg ${ }^{5}$, and Antonio Abellán ${ }^{6}$ \\ ${ }^{1}$ Institute of Photogrammetry and Remote Sensing, Technische Universität Dresden, Dresden, Germany \\ ${ }^{2}$ Soil and Water Conservation Unit, Technical University Freiberg, Freiberg, Germany \\ ${ }^{3}$ Dept. of Rural Engineering, University of Córdoba, Córdoba, Spain \\ ${ }^{4}$ Dept. of Environmental Remote Sensing and Geomatics, University of Trier, Trier, Germany \\ ${ }^{5}$ Dept. of Physical Geography, Catholic University Eichstätt-Ingolstadt, Eichstätt, Germany \\ ${ }^{6}$ Risk Analysis Group, Institute of Earth Sciences, University of Lausanne, Lausanne, Switzerland
}

Correspondence to: Anette Eltner (anette.eltner@tu-dresden.de)

Received: 1 December 2015 - Published in Earth Surf. Dynam. Discuss.: 15 December 2015

Revised: 28 April 2016 - Accepted: 9 May 2016 - Published: 19 May 2016

\begin{abstract}
Photogrammetry and geosciences have been closely linked since the late 19th century due to the acquisition of high-quality 3-D data sets of the environment, but it has so far been restricted to a limited range of remote sensing specialists because of the considerable cost of metric systems for the acquisition and treatment of airborne imagery. Today, a wide range of commercial and open-source software tools enable the generation of 3-D and 4-D models of complex geomorphological features by geoscientists and other non-experts users. In addition, very recent rapid developments in unmanned aerial vehicle (UAV) technology allow for the flexible generation of high-quality aerial surveying and ortho-photography at a relatively low cost.

The increasing computing capabilities during the last decade, together with the development of highperformance digital sensors and the important software innovations developed by computer-based vision and visual perception research fields, have extended the rigorous processing of stereoscopic image data to a 3-D point cloud generation from a series of non-calibrated images. Structure-from-motion (SfM) workflows are based upon algorithms for efficient and automatic orientation of large image sets without further data acquisition information, examples including robust feature detectors like the scale-invariant feature transform for 2-D imagery. Nevertheless, the importance of carrying out well-established fieldwork strategies, using proper camera settings, ground control points and ground truth for understanding the different sources of errors, still needs to be adapted in the common scientific practice.

This review intends not only to summarise the current state of the art on using SfM workflows in geomorphometry but also to give an overview of terms and fields of application. Furthermore, this article aims to quantify already achieved accuracies and used scales, using different strategies in order to evaluate possible stagnations of current developments and to identify key future challenges. It is our belief that some lessons learned from former articles, scientific reports and book chapters concerning the identification of common errors or "bad practices" and some other valuable information may help in guiding the future use of SfM photogrammetry in geosciences.
\end{abstract}




\section{Introduction}

Early works on projective geometries date back to more than five centuries, when scientists derived coordinates of points from several images and investigated the geometry of perspectives (Doyle, 1964). Projective geometry represents the basis for the developments in photogrammetry in the late 19th century, when Aimé Laussedat experimented with terrestrial imagery as well as kites and balloons for obtaining imagery for topographic mapping (Laussedat, 1899). Photogrammetry has rapidly advanced to be an essential tool in geosciences during the last two decades and has lately been gaining momentum driven by digital sensors leading to flexible, fast and facile generation of images. Simultaneously, growing computing capacities and rapid developments in computer vision led to the method of structure from motion (SfM), which opened the way for low-cost, highresolution topography. Thus, the community using imagebased 3-D reconstruction experienced a considerable growth, not only in the quality and detail of the achieved results but also in the number of potential users from diverse geoscientific disciplines.

SfM photogrammetry can be performed with images acquired by consumer-grade digital cameras and is thus very flexible in its implementation. Its ease of use in regard to data acquisition and processing makes it further interesting to non-experts (Fig. 1). The diversity of possible applications led to a variety of terms used to describe SfM photogrammetry either from a photogrammetric or a computer vision standpoint. Thus, to avoid ambiguous terminology, a short list of definitions in regard to the reviewed method is given in Table 1. In this review a series of studies that utilise the algorithmic advance of high automation in SfM are considered - i.e. no initial estimates of the image network geometry or user interactions to generate initial estimates are needed. Furthermore, data processing can be performed almost fully automatically. However, some parameter settings typical for photogrammetric tools (e.g. camera calibration values) can be applied to optimise both accuracy and precision, and ground control point (GCP) or scale identification is still necessary.

SfM photogrammetry can be applied to a vast range of temporal scales (reaching from sub-second to decades) as well as spatial scales (reaching from sub-millimetre to kilometres) and resolutions up to an unprecedented level of detail, allowing for new insights into earth surface processes, i.e. 4-D (three spatial dimensions and one temporal dimension) reconstruction of environmental dynamics. For instance, the concept of sediment connectivity (Bracken et al., 2015) can be approached from a new perspective through varying spatio-temporal scales. Thereby, the magnitude and frequency of events and their interaction can also be evaluated. Furthermore, the versatility of SfM photogrammetry utilising images captured from aerial or terrestrial perspectives has the advantage of being applicable in remote areas with limited access and in fragile, fast-changing environments.

After the suitability of SfM has been noticed for geoscientific applications (James and Robson, 2012; Westoby et al., 2012; Fonstad et al., 2013) the number of studies utilising SfM photogrammetry for geomorphometric investigations (thereby referring to the "science of topographic quantification" based on Pike et al., 2008) has increased significantly. However, the method needs a sophisticated study design and some experience in image acquisition to prevent predictable errors and to ensure good quality of the reconstructed scene. Smith et al. (2015) and Micheletti et al. (2015) recommend a setup for efficient data acquisition.

A total of 65 publications are reviewed in this study. They are chosen according to the respective field of research and methodology. Only those studies that make use of the benefits of automatic image-matching algorithms, and thus apply the various SfM tools, are included. Studies that lack full automation are excluded, i.e. some traditional photogrammetric software. Topic-wise, a line is drawn in regard to the term geosciences. The largest fraction of the reviewed articles tackles questions arising in geomorphological contexts. To account for the versatility of SfM photogrammetry, a few studies deal with plant growth on different scales (moss, crops, forest) or investigate rather exotic topics such as stalagmites or reef morphology.

This review aims to highlight the development of SfM photogrammetry as a valuable tool for geoscientists:

1. The method of SfM photogrammetry is briefly summarised, and algorithmic differences due to their emergence from computer vision as well as photogrammetry are clarified (Sect. 2).

2. Open-source tools regarding SfM photogrammetry are introduced as well as beneficial tools for data postprocessing (Sect. 2).

3. Different fields of applications where SfM photogrammetry led to new perceptions in geomorphometry are displayed (Sect. 3).

4. The performance of the reviewed method is evaluated (Sect. 4).

5. Frontiers and significance of SfM photogrammetry are discussed (Sect. 5).

\section{SfM photogrammetry: method outline}

\subsection{Basic concept}

Reconstruction of three-dimensional geometries from images has played an important role in the past centuries (Ducher, 1987; Collier, 2002). The production of highresolution DEMs was and still is one of the main applications 


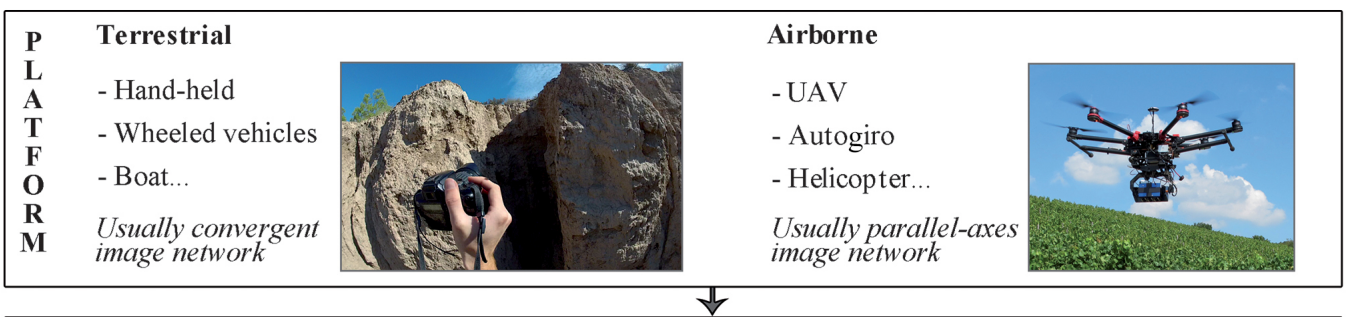

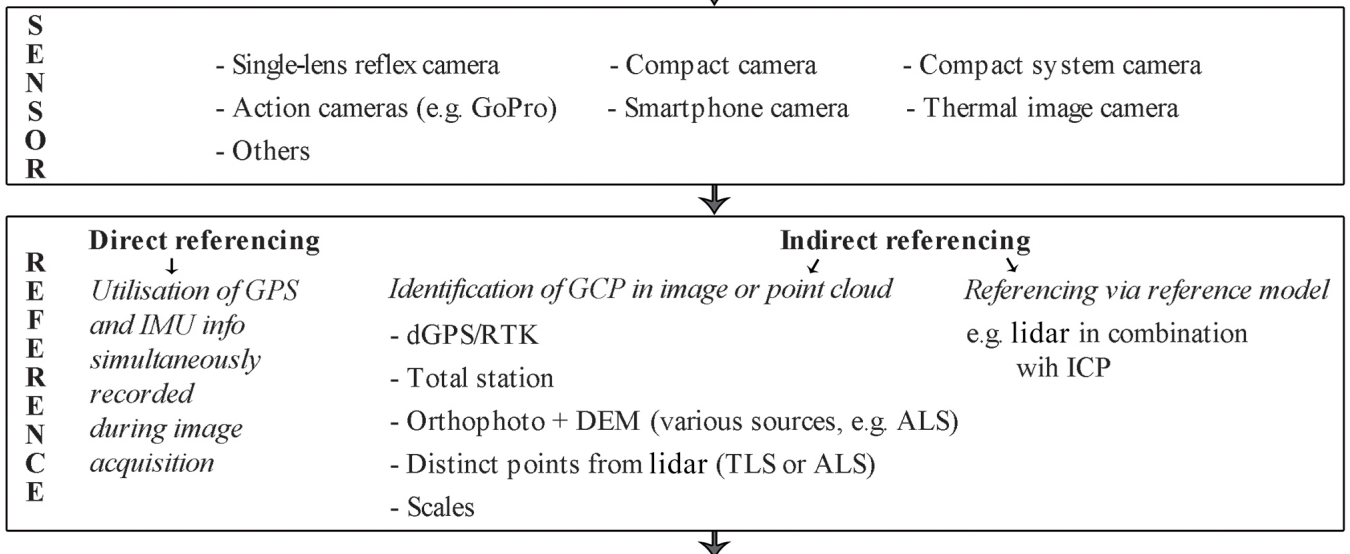

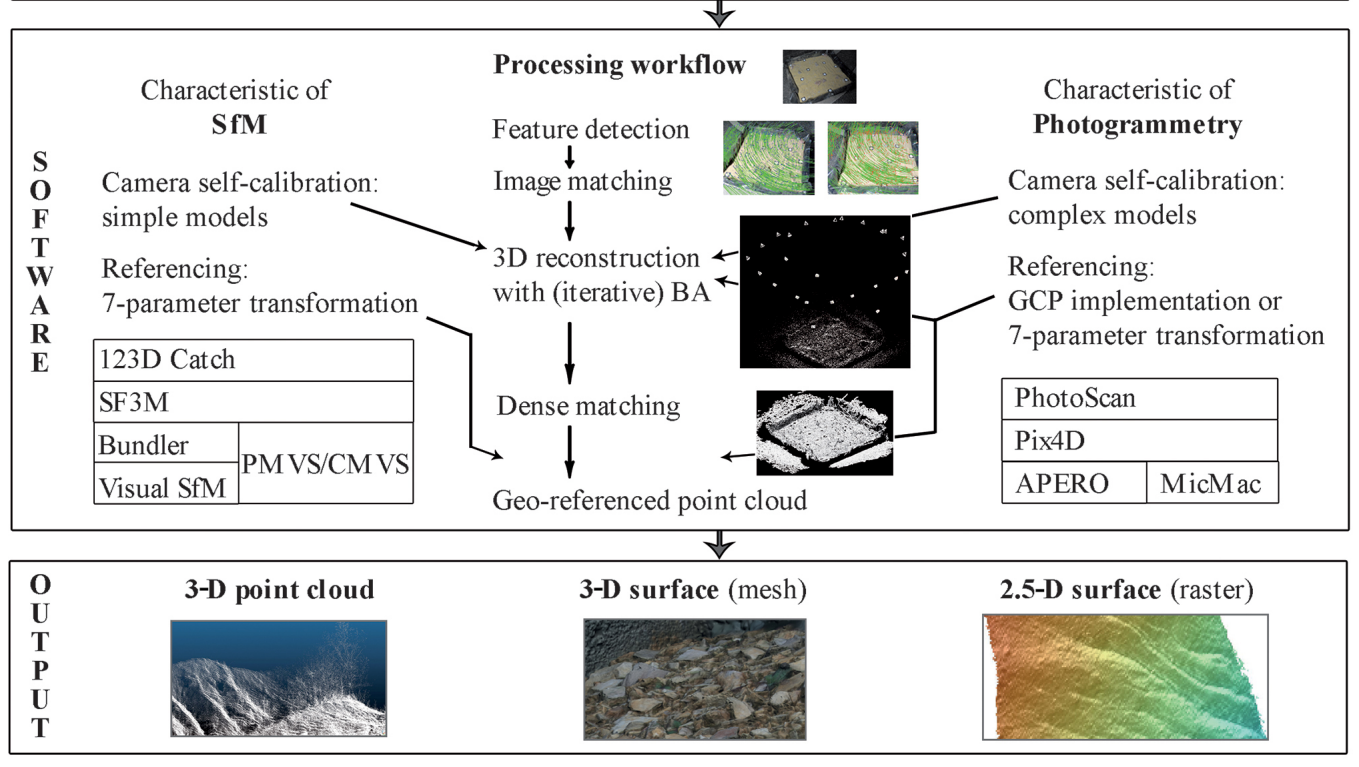

Figure 1. Schematic illustration of the versatility of SfM photogrammetry.

of (digital) photogrammetry. Software and hardware developments as well as the increase in computing power in the 1990 s and early 2000s made aerial photogrammetric processing of large image data sets accessible to a wider community (e.g. Chandler, 1999).

Camera orientations and positions, which are usually unknown during image acquisition, have to be reconstructed to model a 3-D scene. For that purpose, photogrammetry has developed bundle adjustment (BA) techniques, which allow for simultaneous determination of camera orientation and position parameters as well as 3-D object point coordinates for a large number of images (e.g. Triggs et al., 2000). BA needs image coordinates of many tie points as input data. If the BA is extended by a simultaneous calibration option, even the intrinsic camera parameters can be determined in addition to the extrinsic parameters. Furthermore, a series of ground control points can be used as input into BA for geo-referencing the image block (e.g. Luhmann et al., 2014; Kraus, 2007; Mikhail et al., 2001).

Parallel developments in computer vision have taken place that have attempted to reconstruct viewing geometries of image data sets not fulfilling the common prerequisites from digital photogrammetry, i.e. calibrated cameras and initial estimates of the image acquisition scheme. This led to the SfM 
Table 1. Nomenclature and brief definitions of image-based 3-D reconstruction-related terms.

\begin{tabular}{|c|c|}
\hline $\begin{array}{l}\text { Image-based 3-D } \\
\text { reconstruction }\end{array}$ & $\begin{array}{l}\text { recording of the three-dimensional shape of an object from overlapping images } \\
\text { from different perspectives }\end{array}$ \\
\hline Computer vision & $\begin{array}{l}\text { algorithmic efforts to imitate human vision with focus on automation, amongst } \\
\text { other things, to reconstruct } 3 \text {-D scenes with methods of image processing and } \\
\text { image understanding }\end{array}$ \\
\hline $\begin{array}{l}\text { Structure from motion } \\
(\mathrm{SfM})\end{array}$ & $\begin{array}{l}\text { fully automatic reconstruction of } 3 \text {-D scenes from } 2 \text {-D images and simultane- } \\
\text { ous retrieval of the corresponding camera geometry in an arbitrary coordinate } \\
\text { system }\end{array}$ \\
\hline Photogrammetry & $\begin{array}{l}\text { algorithmic efforts to determine } 3 \text {-D model coordinates and camera geometry } \\
\text { focusing on accuracy and precise measurement in images }\end{array}$ \\
\hline SfM photogrammetry & $\begin{array}{l}\text { fully automatic reconstruction of } 3 \text {-D scenes from } 2 \text {-D images and camera ge- } \\
\text { ometry with option to set parameters for (photogrammetric) optimisation of ac- } \\
\text { curacy and precision }\end{array}$ \\
\hline Dense matching & $\begin{array}{l}\text { increase in resolution of point clouds that model 3-D scenes by pixel- or patch- } \\
\text { wise matching in images of known intrinsic and extrinsic parameters }\end{array}$ \\
\hline Stereo matching & $\begin{array}{l}\text { reconstruction of object point through matching (in image space; Remondino et } \\
\text { al., 2014) between two overlapping images }\end{array}$ \\
\hline $\begin{array}{l}\text { Multi-view stereo } \\
\text { (MVS) matching }\end{array}$ & $\begin{array}{l}\text { reconstruction of object point through matching (in object space; Remondino et } \\
\text { al., 2014) from multiple overlapping images }\end{array}$ \\
\hline Extrinsic parameters & $\begin{array}{l}\text { exterior camera geometry comprising position (three shifts) and orientation } \\
\text { (three rotations) of the camera projection centre }\end{array}$ \\
\hline Intrinsic parameters & $\begin{array}{l}\text { interior camera geometry comprising principle distance (distance between pro- } \\
\text { jection centre and image sensor), principle point (intersection of perpendicular } \\
\text { from projection centre onto image plane) and distortion parameters (e.g. radial } \\
\text { distortion) }\end{array}$ \\
\hline $\begin{array}{l}\text { Bundle adjustment } \\
\text { (BA) }\end{array}$ & $\begin{array}{l}\text { least-squares optimisation to simultaneously solve for extrinsic (and intrinsic) } \\
\text { parameters of all images; the term "bundle" correlates to rays that derive from } \\
\text { 3-D points, converge in corresponding projection centres and intersect with im- } \\
\text { age sensor }\end{array}$ \\
\hline Camera self-calibration & $\begin{array}{l}\text { intrinsic camera parameters are included as additional unknowns into BA to } \\
\text { solve for interior camera geometry }\end{array}$ \\
\hline $\begin{array}{l}\text { Ground control point } \\
\text { (GCP) }\end{array}$ & $\begin{array}{l}\text { in images clearly distinguishable point whose object coordinates are known to } \\
\text { geo-reference surface model }\end{array}$ \\
\hline $\begin{array}{l}\text { Digital elevation } \\
\text { model (DEM) }\end{array}$ & 3-D description of the surface in either raster (grid) or vector (mesh) format \\
\hline Point cloud & $\begin{array}{l}\text { quantity of points of } 3 \text {-D coordinates describing the surface within arbitrary or } \\
\text { geo-referenced coordinate system; additional information such as normals or } \\
\text { colours possible }\end{array}$ \\
\hline
\end{tabular}

technique (Ullman, 1979) allowing for processing of large data sets and the use of a combination of multiple non-metric cameras.

The typical workflow of SfM photogrammetry (e.g. Snavely et al., 2008) comprises the following steps:

1. identification and matching of homologous image points in overlapping photos (image matching; e.g. Lowe, 1999);
2. reconstruction of the geometric image acquisition configuration and of the corresponding 3-D coordinates of matched image points (sparse point cloud) with iterative $\mathrm{BA}$;

3. dense matching of the sparse point cloud from reconstructed image network geometry; 
4. scaling or geo-referencing, which is also performable within step 2 .

Smith et al. (2015) give a detailed description of the workflow of SfM photogrammetry, especially regarding step 1 and step 2.

In contrast to classical photogrammetry software tools, SfM allows for reliable processing of a large number of images in rather irregular image acquisition schemes (Snavely et al., 2008) with a much higher degree of process automation. Thus, one of the main differences between the usual photogrammetric workflow and SfM is the emphasis on either accuracy or automation, with SfM focusing on the latter (Pierrot-Deseilligny and Clery, 2011). Another deviation between both 3-D reconstruction methods is the consideration of GCPs (James and Robson, 2014a; Eltner and Schneider, 2015). Photogrammetry performs BA in either one stage, considering GCPs within the BA, or two stages, performing geo-referencing after a relative image network configuration has been estimated (Kraus, 2007). In contrast, SfM is solely performed in the manner of a two-staged BA concentrating on the relative orientation in an arbitrary coordinate system. Thus, absolute orientation has to be conducted separately with a seven-parameter 3-D Helmert transformation, i.e. three shifts, three rotations and one scale. This can be done, for instance, with the freeware tool sfm-georef, which also gives accuracy information (James and Robson, 2012). Using GCPs has been proven to be relevant for specific geometric image network configurations, such as parallel-axes image orientations usual for UAV data, because adverse error propagation can occur due to unfavourable parameter correlation, e.g. resulting in the non-linear error of a DEM dome (Wu, 2014; James and Robson, 2014a; Eltner and Schneider, 2015). Within a one-staged BA these errors are minimised because additional information from GCPs is employed during the adjustment calculation, which is not possible when relative and absolute orientation are not conducted in one stage.

The resulting oriented image block allows for a subsequent dense matching, measuring many more surface points through spatial intersection to generate a DEM with very high resolution. Recent developments in dense matching allow for resolving object coordinates for almost every pixel. To estimate 3-D coordinates, pixel values are either compared in image space in the case of stereo-matching, considering two images, or in the object space in the case of MVS matching, considering more than two images (Remondino et al., 2014). Furthermore, local or global optimisation functions (Brown et al., 2003) are considered, e.g. to handle ambiguities and occlusion effects between compared pixels (e.g. Pears et al., 2012). To optimise pixel matching, (semi-)global constraints consider the entire image or image scan lines (e.g. semi-global matching (SGM) after Hirschmüller, 2011), whereas local constraints consider a small area in the direct vicinity of the pixel of interest (Remondino et al., 2014).
SfM photogrammetry software packages are available partially as freeware or even open-source. Most of the packages comprise SfM techniques in order to derive 3-D reconstructions from any collection of unordered photographs, without the need of providing camera calibration parameters and high-accuracy ground control points. As a consequence, no in-depth knowledge in photogrammetric image processing is required in order to reconstruct geometries from overlapping image collections (James and Robson, 2012; Westoby et al., 2012; Fonstad et al., 2013). Now, however, many photogrammetric tools also utilise abilities from SfM to derive initial estimates automatically (i.e. automation) and then perform photogrammetric BA with the possibility to set weights of parameters for accurate reconstruction performance (i.e. accuracy). In this review, studies are considered which use either straight SfM tools from computer vision or photogrammetric tools implementing SfM algorithms that entail no need for initial estimates in any regard.

\subsection{Tools for SfM photogrammetry and data post-processing}

SfM methodologies rely inherently on automated processing tools which can be provided by different non-commercial or commercial software packages. Within the commercial approach, PhotoScan (Agisoft LLC, Russia), Pix4-D (Pix4-D SA, Switzerland) and MENCI APS (MENCI Software, Italy) represent complete solutions for 3-D photogrammetric processing that have been used in several of the reviewed works.

Initiatives based on non-commercial software have played a significant role in the development of SfM photogrammetry approaches, either (1) open-source, meaning the source code is available with a license for modification and distribution; (2) freely-available, meaning the tool is free to use but no source code is provided; or (3) under free web service with no access to the code, intermediate results or possible secondary data usage (Table 2). The pioneer works by Snavely et al. (2006, 2008) and Furukawa and Ponce (2010) as well as Furukawa et al. (2010) provided the basis to implement one of the first open-source workflows for free SfM photogrammetry combining Bundler and PMVS2/CMVS as in SfMToolkit (Astre, 2015). By 2007, the MicMac project, which is open-source software originally developed for aerial image matching, became available to the public and later evolved to a comprehensive SfM photogrammetry pipeline with further tools such as APERO to estimate image orientation (PierrotDeseilligny and Clery, 2011).

Further contributors put their efforts into offering freely available solutions based on graphical user interfaces (GUIs) for SfM photogrammetry (VisualSfM by Wu, 2013) and geo-referencing (sfm_georef by James and Robson, 2012). The need for editing large point-cloud entities from 3$\mathrm{D}$ reconstruction led to the development of open-source specific tools such as Meshlab (Cignoni et al., 2008) or CloudCompare (Girardeau-Montaut, 2015), also implement- 


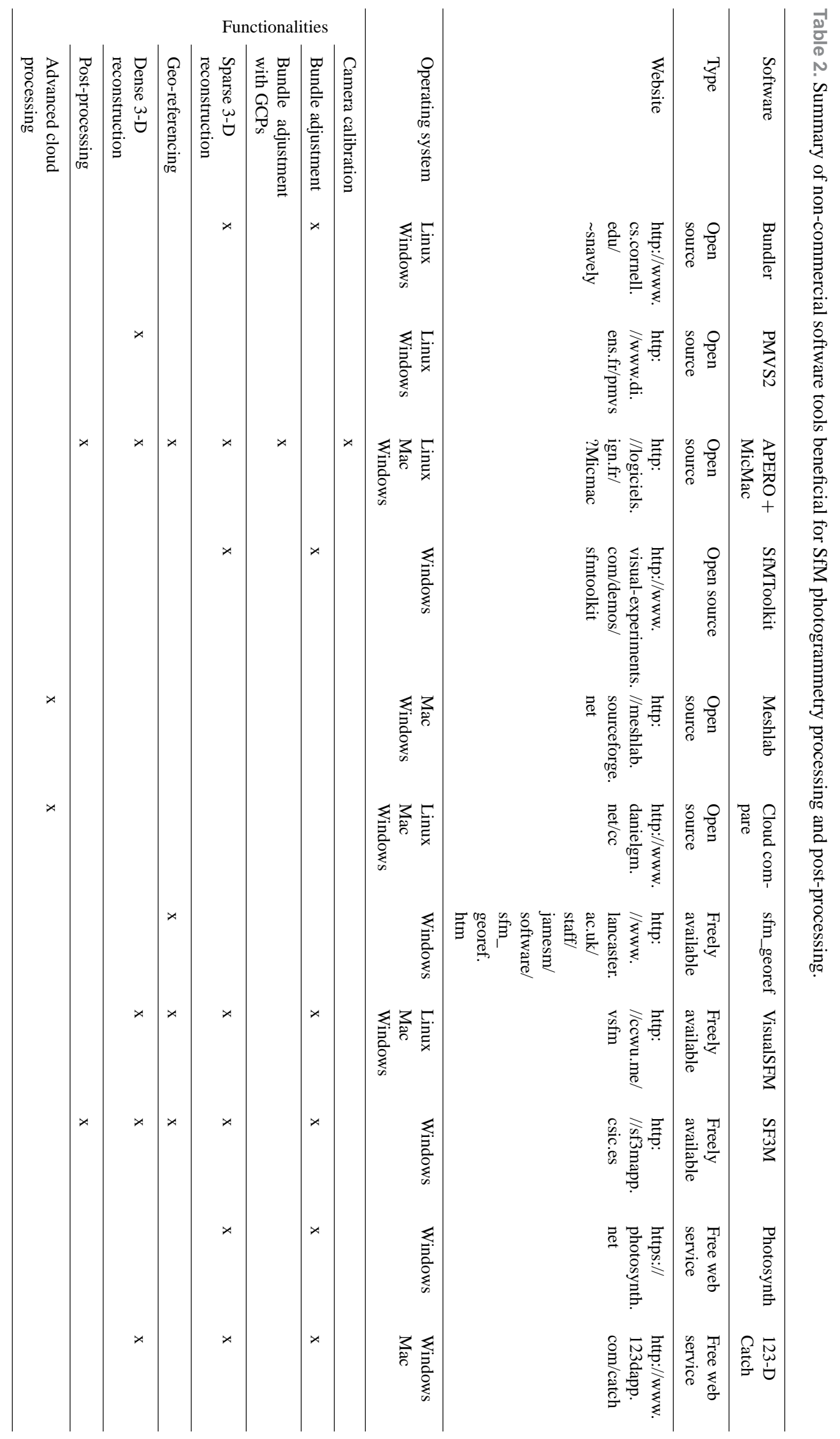


Table 3. Key developments of SfM photogrammetry towards a standard tool in geomorphometry.

\begin{tabular}{ll}
\hline Key developments & authors \\
\hline Method introduction & James and Robson (2012); Westoby et al. (2012); Fonstad et al. (2013) \\
Evaluation of accuracy potential & James and Robson (2012); Westoby et al. (2012); Castillo et al. (2012) \\
SfM with terrestrial images & James and Robson (2012); Westoby et al. (2012); Castillo et al. (2012) \\
SfM with UAV images & Harwin and Lucieer (2012) \\
Application with mm resolution & Bretar et al. (2013); Snapir et al. (2014) \\
Application covering km ${ }^{2}$ & Immerzeel et al. (2014) \\
Mitigation of systematic errors (i.e. dome) & James and Robson (2014a); Eltner and Schneider (2015) \\
Influence of image network geometry & Micheletti et al. (2014); Piermattei et al. (2015) \\
Usage of smartphone for data acquisition & Micheletti et al. (2014) \\
Time-lapse implementation & James and Robson (2014b) \\
Influence of scale & Smith and Vericat (2015) \\
Comparing tools & Stumpf et al. (2014); Eltner and Schneider (2015) \\
Comparing cameras & Eltner and Schneider (2015); Prosdocimi et al. (2015) \\
Synergetic usage of terrestrial and aerial images & Stöcker et al. (2015) \\
Submerged topography & Woodget et al. (2015) \\
Underwater application & Leon et al. (2015) \\
Multi-temporal application & James and Varley (2012); Lucieer et al. (2013) \\
Reuse of historical images & Gomez et al. (2015) \\
\hline
\end{tabular}

ing GUIs. Sf3M (Castillo et al., 2015) exploits VisualSfM and sfm_georef and additional CloudCompare commandline capacities for image-based surface reconstruction and subsequent point cloud editing within one GUI tool. Overall, non-commercial applications have provided a wide range of SfM photogrammetry-related solutions that are constantly being improved on the basis of collaborative efforts. Commercial software packages are not further displayed due to their usual lack of detailed information regarding applied algorithms and their black box approach.

A variety of tools for SfM photogrammetry (at least 10 different) are used within the differing studies of this review (Fig. 3). Agisoft PhotoScan is by far the most employed software, which is probably due to its ease of use. However, this software is commercial and works on the black box principle, which is in contrast to the second most popular tool, Bundler, in combination with PMVS or CMVS. The tool APERO in combination with MicMac focuses on accuracy instead of automation (Pierrot-Deseilligny and Clery, 2011), which is different to the former two. The high degree of possible user-software interaction, which can be very advantageous to adopt the 3-D reconstruction to each specific case study, might also be its drawback because further knowledge into the method is required. Only a few studies have used the software in geoscientific investigations (Bretar et al., 2013; Stumpf et al., 2014; Ouédraogo et al., 2014; Stöcker et al., 2015; Eltner and Schneider, 2015).

\section{Key developments in SfM photogrammetry}

The vast recognition of SfM photogrammetry resulted in a large variety of its implementation leading to methodological developments, which have validity beyond its original ap- plication. Thus, regarding geomorphometric investigations, studies considering the field of applications as well as evaluations of the method's performance induced key advances for SfM photogrammetry to establish as a standard tool in geosciences (Table 3). In the following, the approach is introduced concerning the selection and retrieval of scientific papers utilising SfM photogrammetry.

A survey of 65 scientific papers published between 2012 and 2015 was conducted, covering a wide range of applications of SfM photogrammetry in geoscientific analysis (see Appendix A for a detailed list). Common scientific journals, academic databases and standard online searches have been used to search for corresponding publications. However, it has to be noted that our approach does not guarantee full coverage of the published works using SfM photogrammetry in geosciences. Nevertheless, various disciplines, locations and approaches from all continents are contained in this review (Fig. 2).

To put research hotspots in perspective, it should be taken into account that the number of publications in each discipline is not only dependent on the applicability of the method in that specific field of research. To a greater degree it is closely linked to the overall number of studies, which in the end can probably be broken down to the actual number of researchers in that branch of science. Relative figures revealing the relation between SfM photogrammetry-oriented studies to all studies of a given field of research would be desirable but are beyond the scope of this review.

The previously described advantages of the method have introduced a new group of users, leading to a variety of new studies in geomorphic surface reconstruction and analysis. 


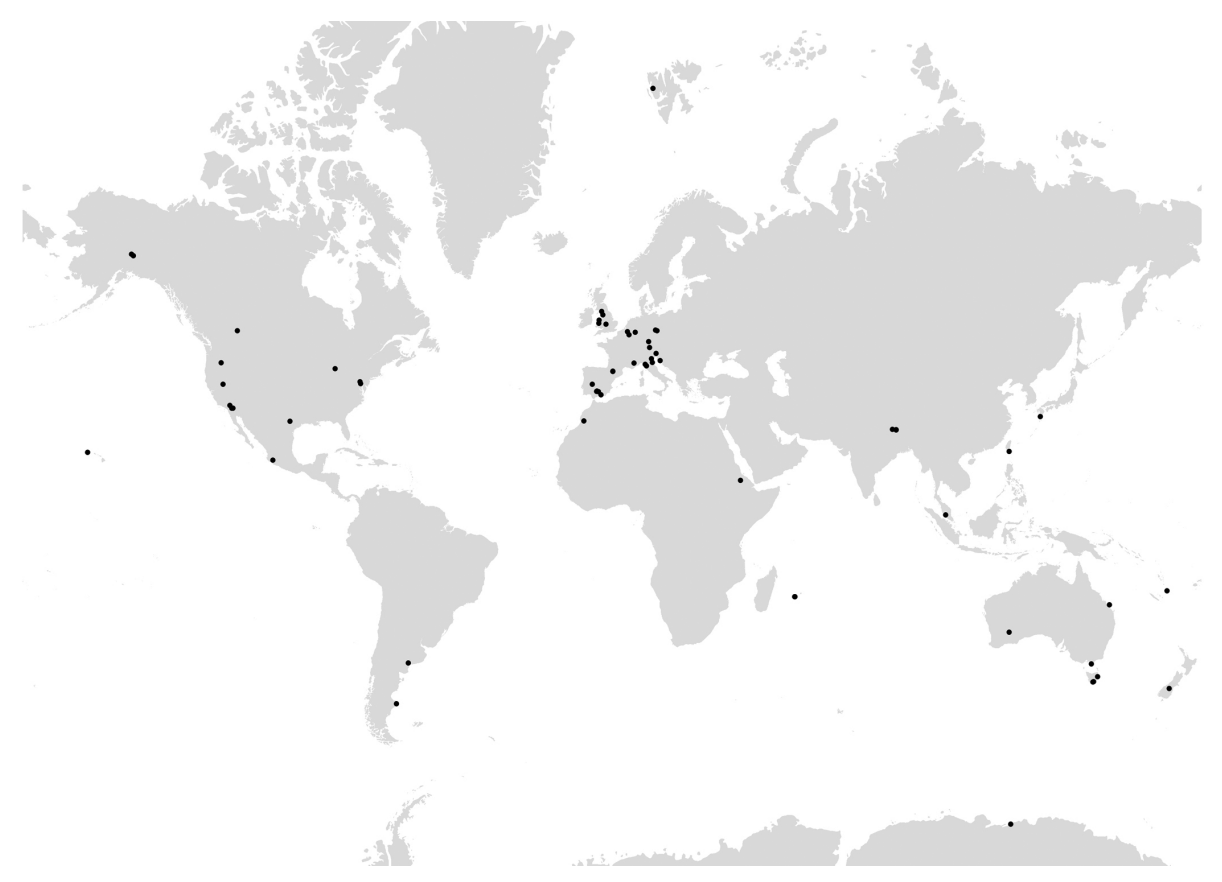

Figure 2. Map of the research sites of all studies of this review.

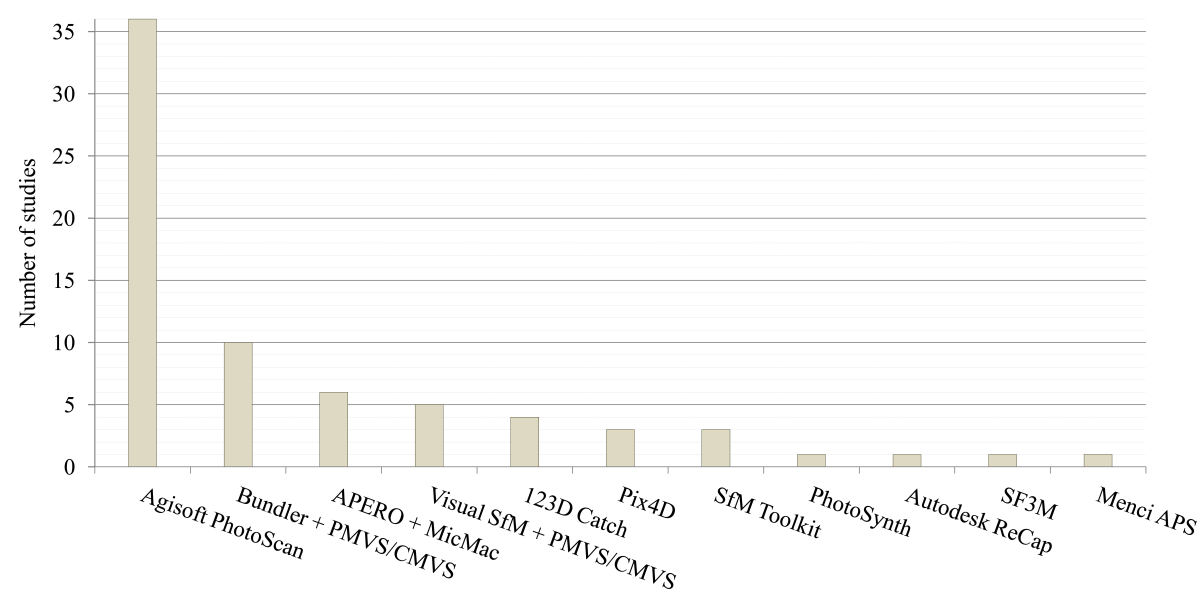

Figure 3. Variety of SfM photogrammetry tools used in the 65 reviewed studies.

Different disciplines started to use SfM algorithms more or less simultaneously.

A list of all topics reviewed in this manuscript according to their year of appearance is shown in Table 4. It is important to note that most subjects are not strictly separable from each other: for instance, a heavy flash flood event will likely trigger heavy damage by soil erosion or upstream slope failures. Thus, corresponding studies are arranged in regard to their major focus. The topic soil science comprises studies of soil erosion as well as soil microtopography.

\subsection{Soil science}

An identification of convergent research topics of SfM photogrammetry in geosciences revealed a distinct focus on erosional processes, especially in soil erosion (11 studies). Gullies, as often unvegetated and morphologically complex features of soil erosion, are predestined to serve as a research object (6 studies) to evaluate SfM performance. One of the first works on SfM in geosciences from 2012 compared established 2-D and 3-D field methods for assessing gully erosion (e.g. lidar, profile meter, total station) to SfM data with regard to costs, accuracy and effectiveness, revealing the superiority of the method (Castillo et al., 2012). Also for a gully system, Stöcker et al. (2015) demonstrated the flexibility of 
Table 4. Overview of the publication history divided into the main topics from 2012 until editorial deadline in November 2015. Several publications examined more than one topic, resulting in a larger number of topics than actual publications (number in brackets in last row). IDs refer to the table in Appendix A1.

\begin{tabular}{|c|c|c|c|c|c|c|c|}
\hline Topic & 2012 & 2013 & 2014 & 2015 & 2016 & ID & $\begin{array}{l}\text { Total number } \\
\text { of publications on } \\
\text { the respective topic }\end{array}$ \\
\hline $\begin{array}{l}\text { Soil } \\
\text { science/erosion }\end{array}$ & 1 & - & 5 & 9 & - & $\begin{array}{l}1,2,3,5,6,9,11 \\
18,22,23,30 \\
31,55,60,61\end{array}$ & 15 \\
\hline Volcanology & 3 & 1 & 1 & 1 & - & $\begin{array}{l}7,15,43,44,52 \\
54\end{array}$ & 6 \\
\hline Glaciology & - & - & 4 & 6 & - & $\begin{array}{l}\begin{array}{l}12,13, \\
27,\end{array} 2,34, \\
51,62\end{array}$ & 10 \\
\hline Mass movements & - & 1 & 1 & 3 & - & $32,35,49,56,64$ & 5 \\
\hline $\begin{array}{l}\text { Fluvial morpho- } \\
\text { logy }\end{array}$ & - & 1 & 5 & 3 & 1 & $\begin{array}{l}4,8,16,17,21 \\
26,29,33,37,38\end{array}$ & 10 \\
\hline $\begin{array}{l}\text { Coastal morpho- } \\
\text { logy }\end{array}$ & 3 & 1 & 3 & - & - & $\begin{array}{l}15,20,28,36 \\
42,50,53\end{array}$ & 7 \\
\hline Others & 1 & 2 & 8 & 5 & - & $\begin{array}{l}7,10,17,19,24, \\
39,40,41,45, \\
46,48,57,58, \\
59,63,65\end{array}$ & 16 \\
\hline $\begin{array}{l}\text { Topics } \\
\text { (publications) }\end{array}$ & $\begin{array}{l}8 \\
(6)\end{array}$ & $\begin{array}{c}6 \\
(6)\end{array}$ & $\begin{array}{c}27 \\
(25)\end{array}$ & $\begin{array}{c}27 \\
(27)\end{array}$ & $\begin{array}{c}1 \\
(1)\end{array}$ & & $\begin{array}{c}69 \\
(65)\end{array}$ \\
\hline
\end{tabular}

camera-based surface reconstruction by combining independently captured terrestrial images with surface models from UAV images to fill data gaps and achieve a comprehensive 3-D model. Large areal coverage and very high resolution allowed for a new quality in the assessment of plot-based soil erosion analysis (Eltner et al., 2015)

Another six studies tackle the 3-D reconstruction of soil microtopography by producing very dense point clouds or DEMs. These data further serve to assess pros and cons of SfM photogrammetry, e.g. detection of small-scale erosion features (Nouwakpo et al., 2014), with regard to the doming effect (Eltner and Schneider, 2015) or as input parameter for erosion modelling (Kaiser et al., 2015).

\subsection{Volcanology}

Volcanology is a pioneering area of SfM photogrammetry research in geosciences because three out of six studies in 2012 included volcanic research sites. James and Robson (2012) acquired information on volcanic dome volume and structural variability prior to an eruption from multi-temporal imagery taken from a light aeroplane. Another interesting work by Bretar et al. (2013) successfully reveals roughness differences in volcanic surfaces from lapilli deposits to slabby pahoehoe lava.

\subsection{Glaciology}

Glaciology and associated moraines are examined in 7 publications. In several UAV campaigns Immerzeel et al. (2014) detected limited mass losses and low surface velocities but high local variations of melt rates that are linked to supraglacial ponds and ice cliffs. Rippin et al. (2015) present another UAV-based work on supra-glacial runoff networks, comparing the drainage system to surface roughness and surface reflectance measurements and detecting linkages between all three. Furthermore, snow depth estimation and rock glacier monitoring are increasingly performed with SfM photogrammetry (Nolan et al., 2015; Dall'Asta et al., 2015).

\subsection{Mass movements}

Compared to the well-established use of lidar techniques on the investigation of landslides (Jaboyedoff et al., 2012), the use of photogrammetric workflows for investigating hazardous slopes is still scarce, which is probably due to the stringent accuracy and safety requirements. For instance, the use of UAV systems for monitoring mass movements using both image correlation algorithms and DEM subtraction techniques has been explored by Lucieer et al. (2013). More recently, SfM techniques were used by Stumpf et al. (2014) 
for monitoring landslide displacements and erosion during several measuring campaigns, including the study of seasonal dynamics on the landslide body, superficial deformation and rockfall occurrence. In addition, these authors assessed the accuracy of two different 3-D reconstruction tools compared to lidar data.

\subsection{Fluvial morphology}

Channel networks in floodplains were surveyed by Prosdocimi et al. (2015) in order to analyse eroded channel banks and to quantify the transported material. Besides classic DSLR cameras, evaluation of an iPhone camera revealed sufficient accuracy, so that in the near future non-scientists will also be able to carry out post-event documentation of damage. An interesting large-scale riverscape assessment is presented by Dietrich (2016), who carried out a helicopterbased data acquisition of a $32 \mathrm{~km}$ river segment. A small helicopter proves to close the gap between unmanned platforms and commercial aerial photography from aeroplanes.

\subsection{Coastal morphology}

In the article by Westoby et al. (2012), several morphological features of contrasting landscapes were chosen to test the capabilities of SfM, one of them being a coastal cliff of roughly $80 \mathrm{~m}$ height. Up to 90000 points $\mathrm{m}^{-2}$ enabled the identification of bedrock faulting. Ružić et al. (2014) produced surface models of coastal cliffs to test the abilities of SfM photogrammetry in undercuts and complex morphologies.

\subsection{Other fields of investigation in geosciences}

In addition to the prevalent fields of attention, more exotic research is also being carried out, unveiling unexpected possibilities for SfM photogrammetry. Besides the benefit for the specific research itself, these branches are important as they either explore new frontiers in geomorphometry or demonstrate the versatility of the method. Lucieer et al. (2014) analyse arctic moss beds and their health conditions by using high-resolution surface topography ( $2 \mathrm{~cm}$ DEM) to simulate water availability from snow melt. Leon et al. (2015) acquired underwater imagery of a coral reef to produce a DEM with a resolution of $1 \mathrm{~mm}$ for roughness estimation. Genchi et al. (2015) used UAV-image data of an urban cliff structure to identify bioerosion features and found a pattern in preferential locations.

The reconsideration of historical aerial images is another interesting opportunity arising from the new algorithmic image-matching developments that allow for new DEM resolutions and thus possible new insights into landscape evolution (Gomez et al., 2015).

\section{Error assessment of SfM photogrammetry in geoscientific applications}

SfM photogrammetry has been tested under a large variety of environments due to the commensurate novel establishment of the method in geosciences, revealing numerous advantages but also disadvantages regarding each application. It is important to have method-independent references to evaluate 3-D reconstruction tools confidently. In total, 39 studies are investigated (Table A1) where a reference has been set up, either area-based (e.g. terrestrial laser scanning, TLS) or point-based (e.g. RTK GPS points). Because not all studies perform accuracy assessment with independent references, the number of studies is in contrast to the number of 65 studies that are reviewed in regard to applications. In the following, methods are illustrated concerning integrated consideration of error performance of SfM photogrammetry in geoscientific studies.

A designation of error parameters is performed prior to comparing the studies to avoid using ambiguous terms. There is a difference between local surface quality and more systematic errors, i.e. due to referencing and project geometry (James and Robson, 2012). Specifically, error can be assessed in regard to accuracy and precision.

Measurement accuracy, which defines the closeness of the measurement to a reference, ideally displays the true surface and can be estimated by the mean error value. However, positive and negative deviations can compensate for each other and thus can impede the recognition of a systematic error (e.g. symmetric tilting) with the mean value. Therefore, numerical and spatial error distribution should also be considered so as to investigate the quality of the measurement (e.g. Smith et al., 2015). For the evaluation of two DEMs, the iterative closest point (ICP) algorithm can improve the accuracy significantly if a systematic linear error (e.g. shifts, tilts or scale variations) is given, as demonstrated by Micheletti et al. (2014). Nevertheless, this procedure can also induce an error when the scene has changed significantly between the two data sets.

Precision, which defines the repeatability of the measurement (for example, it indicates how rough an actual planar surface is represented), usually comprises random errors that can be measured with the standard deviation or RMSE. However, precision is not independent from systematic errors. In this study, the focus lies on RMSE or standard deviation calculated to a given reference (e.g. to a lidar point cloud) and thus the general term "measured error" is used.

Furthermore, error ratios are calculated to compare SfM photogrammetry performance between different studies under varying data acquisition and processing conditions. Thereby, the relative error $\left(e_{\mathrm{r}}\right)$, the reference superiority $\left(e_{\mathrm{s}}\right)$ and the theoretical error ratio $\left(e_{\mathrm{t}}\right)$ are considered. The first is defined as the ratio between measured error and surface to camera distance (Eq. 1). 
$e_{\mathrm{r}}=\frac{\sigma_{\mathrm{m}}}{D}$,

where $e_{\mathrm{r}}$ is the relative error, $\sigma_{\mathrm{m}}$ the measured error and $D$ the mean distance between the camera and surface.

The reference superiority displays the ratio between the measured error and the error of the reference (Eq. 2). It depicts the validity of the reference to be accountable as a reliable data set for comparison.

$e_{\mathrm{s}}=\frac{\sigma_{\mathrm{m}}}{\sigma_{\mathrm{ref}}}$,

where $e_{\mathrm{S}}$ is the reference superiority and $\sigma_{\text {ref }}$ the reference error.

The theoretical error ratio includes the theoretical error, which is an estimate of the theoretically best achievable photogrammetric performance under ideal conditions. It is calculated separately for convergent and parallel-axes image acquisition schemes. The estimate of the theoretical error of depth measurement for the parallel-axis case is displayed by Eq. (3) (more detail in Kraus, 2007). The error is determined for a stereo-image pair and thus might overestimate the error for multi-view reconstruction. Basically, the error is influenced by the focal length, the camera-to-surface distance and the distance between the images of the stereo-pair (base).

$\sigma_{\mathrm{p}}=\frac{D^{2}}{B c} \sigma_{\mathrm{i}}$,

where $\sigma_{\mathrm{p}}$ is the coordinate error for parallel-axes case, $c$ the focal length, $\sigma_{\mathrm{i}}$ the error image measurement and $B$ the distance between images (base).

For the convergent case the error also considers the camera-to-surface distance and the focal length. However, instead of the base the strength of image configuration determined by the angle between intersecting homologous rays is integrated and additionally the employed number of images is accounted for (Eq. 4; more detail in Luhmann et al., 2014).

$\sigma_{\mathrm{c}}=\frac{q D}{\sqrt{k c}} \sigma_{\mathrm{i}}$,

where $\sigma_{\mathrm{c}}$ is the coordinate error for convergent case, $q$ the strength of image configuration, i.e. convergence, and $k$ the number of images.

Finally, the theoretical error ratio is calculated displaying the relation between the measured error and the theoretical error (Eq. 5). The value depicts the performance of SfM photogrammetry in regard to the expected accuracy.

$e_{\mathrm{t}}=\frac{\sigma_{\mathrm{m}}}{\sigma_{\text {theo }}}$,

where $e_{\mathrm{t}}$ is the theoretical error ratio and $\sigma_{\text {theo }}$ the theoretical error, either $\sigma_{\mathrm{p}}$ or $\sigma_{\mathrm{c}}$.
The statistical analysis of the achieved precisions of the reviewed studies is performed with the Python Data Analysis Library (pandas). If several errors are given in one study due to testing of different survey or processing conditions, the error value representing the enhancement of the SfM performance is chosen, i.e. in the study of Javernick et al. (2014) the DEM without an error dome, in the study of Rippin et al. (2015) the linear corrected DEM, and in the study of Eltner and Schneider (2015) the DEMs calculated with undistorted images. In addition, if several approaches are conducted to retrieve the deviation value to the reference, the more reliable error measure is preferred (with regard to Stumpf et al., 2014 and Gómez-Gutiérrez et al., 2014a and 2015). Apart from those considerations, measured errors have been averaged if several values are reported in one study, i.e. concerning multi-temporal assessments or consideration of multiple surfaces with similar characteristics, but not for the case of different tested SfM tools. Regarding data visualisation, outliers that complicated plot drawing were neglected within the concerning graphics. This concerned the study of Dietrich (2016) due to a very large scale of an investigated river reach (excluded from Figs. 4a and 5a-b), the study of Snapir et al. (2014) due to a very high reference accuracy of Lego bricks (excluded from Figs. $4 c$ and 5b), and the study of Frankl et al. (2015) due to a high measured error as the study focus was rather on feasibility than accuracy (excluded from Fig. 5c).

Besides exploiting a reference to estimate the performance of the 3-D reconstruction, registration residuals of GCPs resulting from BA can be taken into account for a first error assessment. But this is not suitable as an exclusive error measure due to potential deviations between the true surface and the calculated statistical and geometric model, which are not detectable with the GCP error vectors alone because BA is optimised to minimise the error at these positions. However, if BA has been performed in two stages (i.e. SfM and referencing calculated separately), the residual vector provides reliable quality information because registration points are not integrated into model estimation.

Error evaluation in this study is performed with reference measurements. Thereby, errors due to the performance of the method itself and errors due to the method of quality assessment have to be distinguished.

\subsection{Error sources of SfM photogrammetry}

The error of 3-D reconstruction is influenced by many factors: scale/distance, camera calibration, image network geometry, image-matching performance, surface texture and lighting conditions, and GCP characteristics, which are examined in detail in this section. 

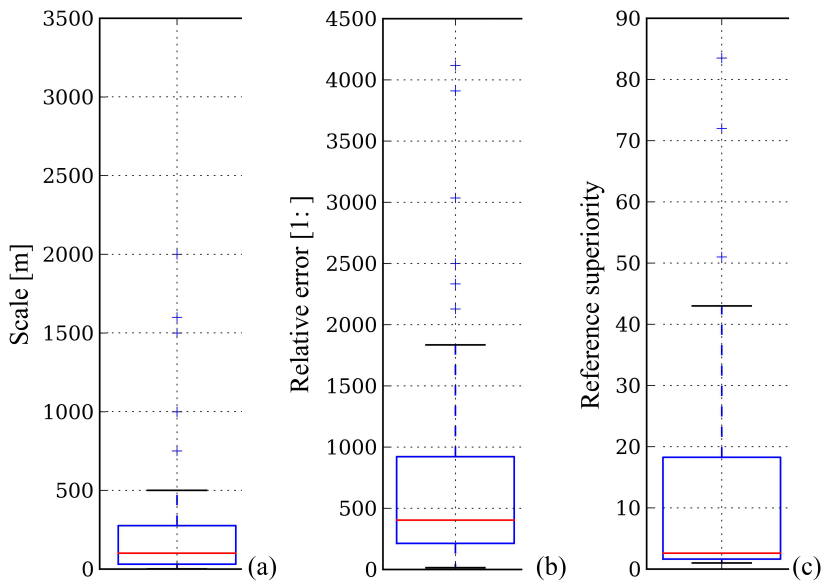

Figure 4. Box plots summarising statistics: (a) of the scale of the study reaches (N: 56; ID 1-3 and 5-39 in Appendix A), (b) the relative error (calculated in regard to distance and measured error, $\mathrm{N}$ : 54; ID 1-3, 5-12 and 14-39 in Appendix A), and (c) the reference superiority (calculated in regard to measured error and reference error, N: 33; ID 1-30 and 32-39 in Appendix A) of reviewed studies.

\subsubsection{Scale and sensor to surface distance}

SfM photogrammetry has the advantage of being useable at almost any scale. Thus, in the reviewed studies the method is applied at a large range of scales (Fig. 4a), reaching from $10 \mathrm{~cm}$ for volcanic bombs (Favalli et al., 2012; James and Robson, 2012) up to $10 \mathrm{~km}$ for a river reach (Dietrich, 2016). Median scale amounts to about $100 \mathrm{~m}$. SfM photogrammetry reveals a scale-dependent practicability (Smith and Vericat, 2015) if case-study-specific tolerable errors are considered, e.g. for multi-temporal assessments. For instance, at plot and hillslope scale, 3-D reconstruction is a very sufficient method for soil erosion studies, even outperforming TLS (Nouwakpo et al., 2015; Eltner et al., 2015; Smith and Vericat, 2015). The method should be most useful in small-scale study reaches (Fonstad et al., 2013), whereas error behaviour is not as advantageous for larger scales, i.e. catchments (Smith and Vericat, 2015).

Besides scale, the distance between sensor and surface is important for image-based reconstructed DEM error, also because scale and distance interrelate. The comparison of the reviewed studies indicates that with an increase in distance the measured error increases, which is not unexpected (Fig. 5a, circles). However, there is no linear trend detectable. Therefore, the relative error is not assignable. The relative error displays a large range from 15 to 4000 with a median of 400, thus revealing a rather low error potential (Fig. 5a, triangles). Very high ratios are solely observable for very closerange applications and at large distances. A general increase in the relative error with distance is observable (Fig. 5a, triangles). The indication that centimetre-accurate measurements are realisable at distances below $200 \mathrm{~m}$ (Stumpf et al., 2014) can be confirmed by Fig. 5a because most deviations are be-
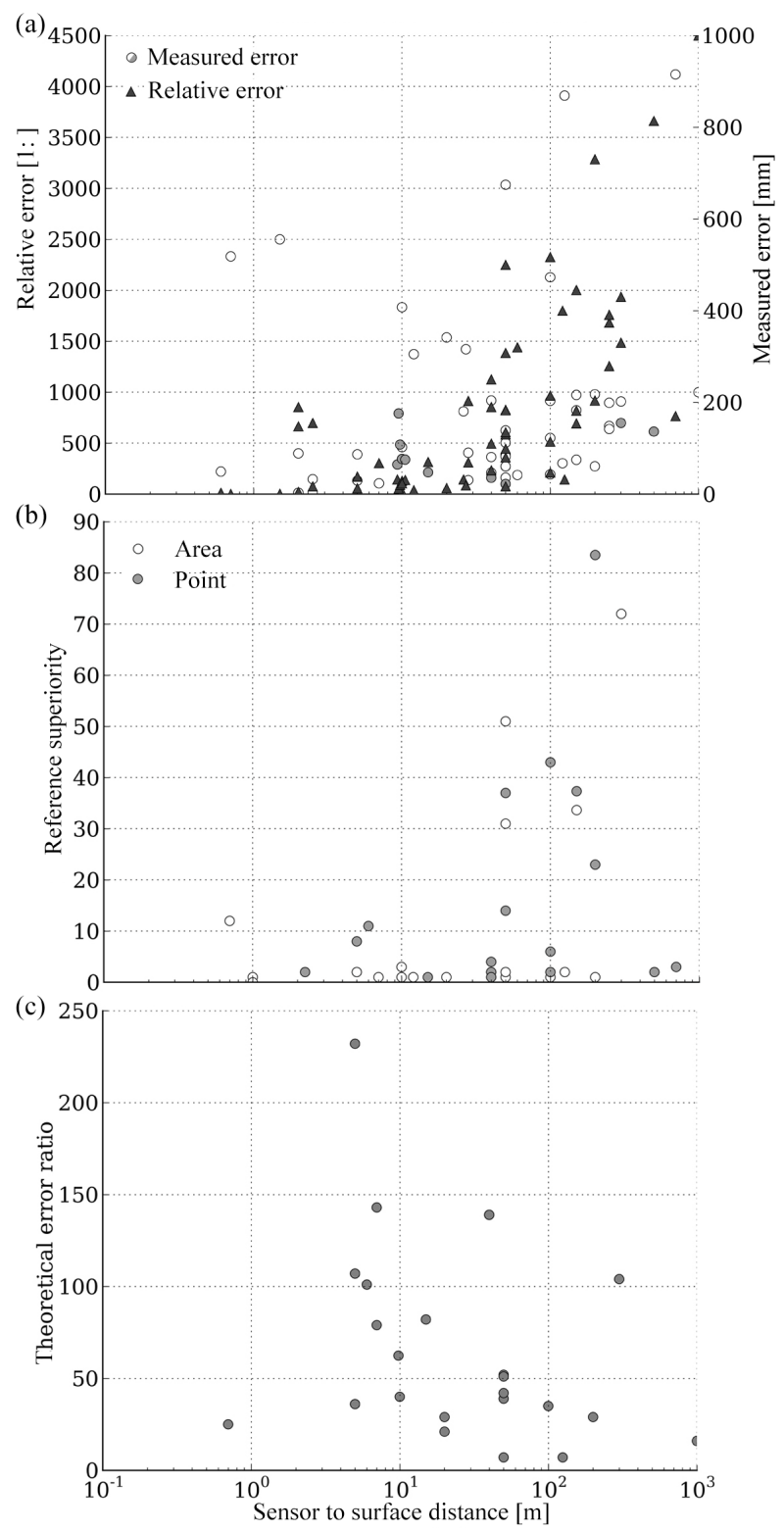

Figure 5. Performance of several error parameters in regard to the camera-to-surface distance. (a) Characteristics of measured error and relative error (N: 54; ID 1-3, 5-12 and 14-39 in Appendix A). For grey-coloured points GCPs are measured in point cloud (in total 9 times corresponding to the studies: ID 8, 11, 12, 28, 36 and 37 in Appendix A) and for white points GCPs are measured in images (corresponding to the remaining studies) for model transformation. (b) Superiority of the reference data $(\mathrm{N}: 33)$, which is calculated as ratio between measured error and error of the reference. Area-based (ID 5-7, 12, 15, 17, 22, 25, 26, 30 and 32 in Appendix A) and pointbased (ID 2, 3, 8, 9, 20, 24, 28-30, 33, 35 and 37 in Appendix A) reference measurements are distinguished. (c) Theoretical error ratio, considering the theoretical and measured error, to illustrate SfM photogrammetry performance in field applications (N: 23; ID 1-3, $8,10-12,15,21,22,25,26,28-30$ and 32 in Appendix A). 
low $10 \mathrm{~cm}$ up to that range. Overall, absolute error values are low at close ranges, whereas the relative error is higher at larger distances.

\subsubsection{Camera calibration}

SfM photogrammetry allows for straightforward handling of camera options due to integrated self-calibration, but knowledge about some basic parameters is necessary to avoid unwanted error propagation into the final DEM from insufficiently estimated camera models. The autofocus as well as automatic camera stabilisation options should be deactivated if a pre-calibrated camera model is used or one camera model is estimated for the entire image block because changes in the interior camera geometry due to camera movement cannot be captured with these settings. The estimation of a single camera model for one image block is usually preferable, if a single camera has been used, whose interior geometry is temporary stable, to avoid over-parameterisation (PierrotDeseilligny and Clery, 2011). Thus, if zoom lenses are moved a lot during data acquisition, they should be avoided due to their instable geometry (Shortis et al., 2006; Sanz-Ablanedo et al., 2010) that impedes usage of pre-calibrated fixed or single camera models. A good compromise between camera stability, sensor size and equipment weight, which is more relevant for UAV applications, is achieved by compact system cameras (Eltner and Schneider, 2015). However, solely three studies utilise compact system cameras in the reviewed studies (Tonkin et al., 2014; Eltner and Schneider, 2015; Eltner et al., 2015).

Along with camera settings, the complexity in regard to the considered parameters of the defined camera model within the 3-D reconstruction tool is relevant as well as the implementation of GCPs to function as further observations in the BA, i.e. to avoid DEM domes as a consequence of insufficient image distortion estimation (James and Robson, 2014a; Eltner and Schneider, 2015). Also, Stumpf et al. (2014) detect worse distortion correction with a basic SfM tool, considering a simple camera model, compared to more complex software, integrating a variety of camera models and GCP consideration. Camera calibration is a key element for high DEM quality, which is extensively considered in photogrammetric software, whereas simpler models that solely estimate principle distance and radial distortion are usually implemented in the SfM tools originating from computer vision (Eltner and Schneider, 2015; James and Robson, 2012; Pierrot-Deseilligny and Clery, 2011).

\subsubsection{Image resolution}

Image resolution is another factor influencing the final DEM quality. In particular, the absolute pixel size needs to be accounted for due to its relevance for the signal-to-noise ratio (SNR) because the larger the pixel the higher the amount of light that can be captured and hence a more distinct sig- nal is measured. Resolution alone by means of pixel number gives no information about the actual metric sensor size. A large sensor with large pixels and a large number of pixels provides better image quality due to reduced image noise than a small sensor with small pixels but the same number of pixels. Thus, high image resolution defined by large pixel numbers and pixel sizes results in sufficient quality of images and thus DEMs (Micheletti et al., 2014; Eltner and Schneider, 2015).

However, the reviewed investigations indicate no obvious influence of the pixel size at the DEM quality. Mostly, cameras with middle-sized sensors and corresponding pixel sizes around $5 \mu \mathrm{m}$ are used and a large range of errors at different pixel sizes is given.

To speed up processing, down-sampling of images is often performed, causing interpolation of pixels and thus the reduction of image information, which can be the cause of underestimation of high-relief changes, e.g. observed by Smith and Vericat (2015) or Nouwakpo et al. (2015). Interestingly, Prosdocimi et al. (2015) reveal that lower errors are possible with decreasing resolution due to an increase in error smoothing. Nevertheless, image data collection in the field should be done at highest realisable resolution and highest SNR to fully keep control over subsequent data processing - i.e. data smoothing should be performed under selfdetermined conditions at the desktop, which is especially important for studies of rough surfaces to allow for probate error statistics (e.g. Brasington et al., 2012).

\subsubsection{Image network geometry}

In regard to the geometry of the image network, several parameters are important: number of images, image overlap, obliqueness and convergence.

At least three images need to capture the area of interest, but for redundancy and to decrease DEM error, higher numbers are preferred (James and Robson, 2012). For instance, Piermattei et al. (2015) detect better qualities for a higher number of images. However, the increase in images does not linearly increase the accuracy (Micheletti et al., 2014), and may ultimately lead to unnecessary increase in computation time. Generally, image number should be chosen depending on the size and complexity of the study reach (James and Robson, 2012), i.e. as high as possible but still keeping in mind acceptable processing time.

High image overlap is relevant to finding homologous points within many images that cover the entire image space. Stumpf et al. (2014) show that higher overlap resolves in better results. Wide-angle lenses whose radial distortion is within the limits should be chosen for data acquisition.

The reviewed studies reveal a large variety of applicable perspectives for DEM generation. Most applications use images captured from the ground, which is the most flexible implementation of the SfM photogrammetry method. In regard to terrestrial or aerial perspective, Smith and Ver- 
icat (2015) state that aerial images should be preferred if plots reach sizes larger than $100 \mathrm{~m}$, because at these distances obliqueness of images becomes too unfavourable. Stumpf et al. (2014) even mention a distinct value of the incidence angle of $30^{\circ}$ to the captured surface above which data quality decreases significantly.

Furthermore, image network geometry has to be considered separately for convergent acquisitions schemes, common for terrestrial data collection, and for parallel-axes acquisition schemes, common for aerial data collection. The parallel-axes image configuration results in unfavourable error propagation due to unfavourable parameter correlation, which inherits the separation between DEM shape and radial distortion (James and Robson, 2014a; Wu, 2014), resulting in a dome error that needs either GCP implementation or a well-estimated camera model for error mitigation (James and Robson, 2014a; Eltner and Schneider, 2015). However, GCP accuracy has to be sufficient or else the weight of GCP information during BA is too low to avoid unfavourable correlations, as shown by Dietrich (2016), where DEM dome error within a river reach could not be diminished even though GCPs were implemented into 3-D reconstruction. If convergent images are utilised, the angle of convergence is important, because the higher the angle, the better the image network geometry. Thereby, accuracy increases because sufficient image overlap is possible with larger bases between images. Therefore, glancing ray intersections, which impede distinct depth assignment, are avoided. But, at the same time, convergence should not be so high that the imaged scene becomes too contradictory for successful image matching (Pierrot-Deseilligny and Clery, 2012; Stöcker et al., 2015).

\subsubsection{Accuracy and distribution of homologues image points}

The quality of DEMs reconstructed from overlapping images depends significantly on the image-matching performance (Gruen, 2012). Image content and type, which cannot be enhanced substantially, are the primary factors controlling the success of image matching (Gruen, 2012). Image matching is important for reconstruction of the image network geometry as well as the subsequent dense matching.

On the one hand, it is relevant to find good initial matches (e.g. SIFT features are not as precise as least-squares matches with 1/10 pixel size accuracies; Gruen, 2012) to perform reliable 3-D reconstruction and thus retrieve an accurate sparse point cloud because optimisation procedures for model refinement rely on this first point cloud. Thus, immanent errors will propagate along the different stages of SfM photogrammetry.

On the other hand, image-matching performance is more obviously important for dense reconstruction, when 3-D information is calculated for almost every pixel. The accuracy of intersection during dense matching depends on the accuracy of the estimated camera orientations (Remondino et al., 2014). If the quality of the DEM is the primary focus, which is usually not the case for SfM algorithms originating from computer vision, the task of image matching is still difficult (Gruen, 2012). Nevertheless, newer approaches are emerging, though, which still need evaluation in respect of accuracy and reliability (Remondino et al., 2014). An internal quality control for image matching is important for DEM assessment (Gruen, 2012), but is mostly absent in tools for SfM photogrammetry.

So far, many studies exist which evaluate the quality of 3D reconstruction in geoscientific applications. Nevertheless, considerations of dense-matching performance are still missing, especially in regard to rough topographies (Eltner and Schneider, 2015).

\subsubsection{Surface texture}

Texture and contrast of the area of interest are significant to identify suitable homologous image points. Low textured and contrasted surfaces result in a distinct decrease in image features, i.e. snow-covered glaciers (Gómez-Gutiérrez et al., 2014a) or sandy beaches (Mancini et al., 2013). Furthermore, vegetation cover complicates image-matching performance due to its highly variable appearance from differing viewing angles (e.g. Castillo et al., 2012; Eltner et al., 2015) and possible movements during wind. Thus, in this study, where present, only studies of bare surfaces are reviewed for error assessment.

\subsubsection{Illumination condition}

Over- and underexposure of images is another cause of error in the reconstructed point cloud, which cannot be significantly improved by utilising high-dynamic-range (HDR) images (Gómez-Gutiérrez et al., 2015). Well-illuminated surfaces result in a high number of detected image features, which is demonstrated for coastal boulders under varying light conditions by Gienko and Terry (2014). Furthermore, Gómez-Gutiérrez et al. (2014a) highlight the unfavourable influence of shadows because highest errors are measured in these regions; interestingly, these authors calculate the optimal time for image acquisition from the first DEM for multitemporal data acquisition. Furthermore, the temporal length of image acquisition needs to be considered during sunny conditions because with increasing duration shadow changes can decrease matching performance - i.e. with regard to the intended quality, surveys lasting more than $30 \mathrm{~min}$ should be avoided (Bemis et al., 2014). Generally, overcast but bright days are most suitable for image capture to avoid strong shadows or glared surfaces (James and Robson, 2012).

\subsubsection{GCP accuracy and distribution}

GCPs are important inputs for data referencing and scaling. Photogrammetry always stresses the weight of good 
ground control for accurate DEM calculation, especially if one-staged BA is performed. In the common SfM workflow, integration of GCPs is less demanding because they are only needed to transform the 3-D model from the arbitrary coordinate system, which is comparable to the photogrammetric two-staged BA processing. A minimum of three GCPs are necessary to account for model rotation, translation and scale. However, GCP redundancy, i.e. more points, has been shown to be preferable to increase accuracy (James and Robson, 2012). A high number of GCPs further ensures the consideration of checkpoints not included for the referencing, which are used as independent quality measure of the final DEM. More complex 3-D reconstruction tools either expand the original 3-D Helmert transformation by secondary refinement of the estimated interior and exterior camera geometry to account for non-linear errors (e.g. Agisoft PhotoScan) or integrate the ground control into the BA (e.g. APERO). For instance, Javernick et al. (2014) were able to reduce the height error to decimetre level by including GCPs in the model refinement.

Natural features over stable areas, which are explicitly identifiable, are an alternative for GCP distributions, although they usually lack strong contrast (as opposed to artificial GCPs) that would allow for automatic identification and sub-pixel accurate measurement (e.g. Eltner et al., 2013). Nevertheless, they can be suitable for multi-temporal change detection applications, where installation of artificial GCPs might not be possible (e.g. glacier surface reconstruction; Piermattei et al., 2015) or necessary as in some cases relative accuracy is preferred over absolute performance (e.g. observation of landslide movements; Turner et al., 2015).

GCP distribution needs to be even and adapted to the terrain resulting in more GCPs in areas with large changes in relief (Harwin and Lucieer, 2012) to cover different terrain types. Harwin and Lucieer (2012) state an optimal GCP distance between $1 / 5$ and $1 / 10$ of object distance for UAV applications. Furthermore, the GCPs should be distributed widely across the target area (Smith et al., 2015) and at the edge or outside the study reach (James and Robson, 2012) to enclose the area of interest, because if the study area is extended outside the GCP area, a significant increase in error is observable in that region (Smith et al., 2014; Javernick et al., 2014; Rippin et al., 2015). If data acquisition is performed with parallel-axis UAV images and GCPs are implemented for model refinement, rules for GCP setup according to classical photogrammetry apply, i.e. dense GCP installation around the area of interest and height control points in specific distances as function of image number (more detail in e.g. Kraus, 2007).

The measurement of GCPs can be performed within either the point cloud or the images, preferring the latter because identification of distinct points in 3-D point clouds of varying density can be less reliable (James and Robson, 2012; Harwin and Lucieer, 2012) compared to sub-pixel measurement in 2-D images, where accuracy of GCP identification basically depends on image quality. Figure 5a illustrates that only a few studies have measured GCPs in point clouds, resulting higher errors compared to other applications at the same distance.

\subsection{Errors due to accuracy/precision assessment technique}

\subsubsection{Reference of superior accuracy}

It is difficult to find a suitable reference for error assessment of SfM photogrammetry in geoscientific or geomorphologic applications due to the usually complex and rough nature of the studied surfaces. So far, either point-based or area-based measurements have been carried out. On the one hand, point-based methods (e.g. RTK GPS or total station) ensure superior accuracy but lack sufficient area coverage for precision statements of local deviations; on the other hand, area-based (e.g. TLS) estimations are used, which provide enough data density but can be lacking in sufficient accuracy (Eltner and Schneider, 2015). Roughness is the least constrained error within point clouds (Lague et al., 2013) independent from the observation method. Thus, it is difficult to distinguish between method noises and the actual signal of method differences, especially at scales where the reference method reaches its performance limit. For instance, Tonkin et al. (2014) indicate that the quality of total station points is not necessarily superior on steep terrain.

Generally, $75 \%$ of the investigations reveal a measured error that is 20 times higher than the error of the reference. But the median shows that the superiority of the reference accuracy is actually significantly poorer; the measured error is merely twice the reference error (Fig. 4c). The reviewed studies further indicate that the superior accuracy of the reference seems to depend on the camera-to-object distance (Fig. 5b). At shorter distances (below $50 \mathrm{~m}$ ) most references reveal accuracies that are lower than one magnitude superiority to the measured error. However, alternative reference methods are still absent. For applications solely in further distances the references are sufficient. These findings are relevant for the interpretation of the relative error because low ratios at smallscale reaches might be due to the low performance of the reference rather than the actual 3-D reconstruction quality, but due to the reference noise lower errors they are not detectable. Low relative errors are measured where the superior accuracy is also low (distance $5-50 \mathrm{~m}$ ) and large ratios are given at a distance where superior accuracy increases as well.

\subsubsection{Type of deviation measurement}

The reviewed studies use different approaches to measure the distance between the reference and the 3-D reconstructed surface. Comparisons are performed in either 2.5-D (raster) or real 3-D (point cloud). Lague et al. (2013) highlight that 
the application of raster inherits the disadvantage of data interpolation, especially relevant for rough surfaces or complex areas (e.g. undercuts as demonstrated for gullies by Frankl et al., 2015). In this context it is important to note that lower errors are measured for point-to-point distances rather than raster differencing (Smith and Vericat, 2015; GómezGuiérrez et al., 2014b).

Furthermore, within 3-D evaluation, different methods for deviation measurement exist. The point-to-point comparison is solely suitable for a preliminary error assessment because this method is prone to outliers and differing point densities. By point cloud interpolation alone (point-to-mesh), this issue is not solvable because there are still problems at very rough surfaces (Lague et al., 2013). Different solutions have been proposed: on the one hand, Abellán et al. (2009) proposed averaging the point cloud difference along the spatial dimension, which can also be extended to 4-D $(x, y$, $z$, time; Kromer et al., 2015). On the other hand, Lague et al. (2013) proposed the M3C2 algorithm for point cloud comparison that considers the local roughness and further computes the statistical significance of detected changes. Stumpf et al. (2014) and Gómez-Gutiérrez et al. (2015) illustrated lower error measurements with $\mathrm{M} 3 \mathrm{C} 2$ compared to point-topoint or point-to-mesh. Furthermore, Kromer et al. (2015) showed how the 4-D filtering, when its implementation is feasible, allows for a considerably increase in the level of detection compared to other well-established techniques of comparison.

\subsection{Standardised error assessment}

To compare the achieved accuracies and precisions of different studies a standardised error assessment is necessary, e.g. considering the theoretical error ratio. The calculation of the theoretical error for the convergent image acquisition schemes is possible, making some basic assumptions about the network geometry, i.e. the strength of image configuration equals 1 (as in James and Robson, 2012), the number of images equals 3 (as in James and Robson, 2012) and an image measurement error of 0.29 due to quantisation noise (as a result of continuous signal conversion to discrete pixel value). However, it is not possible to evaluate the theoretical error for parallel-axes case studies because information about the distance between subsequent images (base) is mostly missing but essential to solve the equation and should not be assumed. Eltner and Schneider (2015) and Eltner et al. (2015) compare their results to parallel-axes theoretical error and demonstrate that photogrammetric accuracy is at least possible for soil surface measurement from low flying heights (e.g. sub-centimetre error for altitudes around $10 \mathrm{~m}$ ).

The results from James and Robson (2012), which show a less reliable performance of SfM than expected from photogrammetric estimation, can be confirmed by the reviewed studies. Image-based 3-D reconstruction, considering SfM workflows, performs poorer than the theoretical er- ror (Fig. 5c). The measured error is always higher and on average 90 times worse than the theoretical error. Even for the smallest theoretical error ratio the actual error is 6 times higher. Furthermore, it seems that with increasing distance theoretical and measured errors converge slightly.

As demonstrated, diverse factors influence SfM photogrammetry performance and subsequent DEM error with different sensitivity. Generally, accurate and extensive data acquisition is necessary to minimise error significantly (Javernick et al., 2014). Independent reference sources, such as TLS, are not replaceable (James and Robson, 2012) due to their differing error properties (i.e. error reliability) compared to image matching (Gruen, 2012). Synergetic effects of SfM and classical photogrammetry should be used, i.e. benefiting from the high automation of SfM to retrieve initial estimates without any prior knowledge about the image scene and acquisition configuration and adjacent reducing error by approved photogrammetric approaches which are optimised for high accuracies.

The reviewed studies indicate the necessity of a standardised protocol for error assessment because the variety of studies inherit a variety of scales worked at, software used, GCP types measured, deviation measures applied, image network configurations implemented, cameras and platforms operated and reference utilised, making it very difficult to compare results with consistency. Relevant parameters for a standard protocol are suggested in Fig. 6.

\section{Perspectives and limitations}

SfM photogrammetry has allowed for creation of massive three-dimensional data sets by non-specialists during the last five years, and it is highly expected that this technique will evolve during the next decade. Current studies are focusing on capturing the terrain's geometry with high precision, but several opportunities to improve our understanding, modelling and prediction of different earth surface processes still remain unexplored. For instance, the use of super-macro imagery in conventional SfM workflows is expected to be explored soon for investigating natural phenomena in a much higher level of detail. Nevertheless, some technological issues that need to be addressed include the progressive degradation of the data quality at very short distances due to the effect of a limited depth of field; to our knowledge, the use of focus stacking for extending shallow depth of field of single images has not been explored yet. Some other technical and operational aspects are still limiting our ability to derive 3-D point clouds from digital imagery over naturally complex outcrops. Examples include the occurrence of biases and occlusions that can strongly influence the quality of the acquired data sets and the progressive reduction of the ground resolution (metre/pixel) at longer distances, which can be addressed using mobile platforms such as UAV systems. Eventually, the SfM photogrammetry technique may become a mainstream procedure in geomorphological stud- 


\begin{tabular}{|c|c|c|c|c|}
\hline \multicolumn{5}{|c|}{ In the field: } \\
\hline \multirow{4}{*}{ 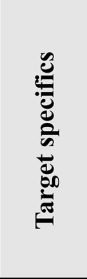 } & $\begin{array}{l}\text { Study area } \\
\text { extent }\end{array}$ & \multirow{4}{*}{ 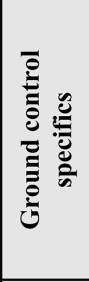 } & \begin{tabular}{|l|} 
GCP measurement \\
{$[$ total station, GPS, ... $]$}
\end{tabular} & \\
\hline & $\begin{array}{l}\text { Sensor to surface } \\
\text { distance }\end{array}$ & & GCP description & \\
\hline & $\begin{array}{l}\text { Ground sampling } \\
\text { distance }\end{array}$ & & GCP number & \\
\hline & $\begin{array}{l}\text { Target } \\
\text { complexity }\end{array}$ & & GCP accuracy & \\
\hline \multirow{7}{*}{ 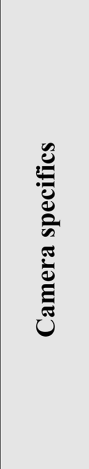 } & Camera name & \multirow{6}{*}{ 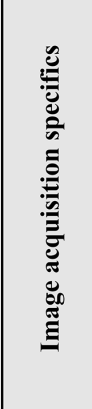 } & Illumination condition & \\
\hline & $\begin{array}{l}\text { Camera type } \\
{[\text { SLR, CSC }, . . .]}\end{array}$ & & Image number & \\
\hline & $\begin{array}{l}\text { Lens type [zoom } \\
\text {-fixed] }\end{array}$ & & Image overlap & \\
\hline & $\begin{array}{l}\text { Sensor } \\
\text { resolution }\end{array}$ & & $\begin{array}{l}\text { Base [distance } \\
\text { between images] }\end{array}$ & \\
\hline & Sensor size & & $\begin{array}{l}\text { Network configuration } \\
\text { [conv.-parallel-axis] }\end{array}$ & \\
\hline & Pixel size & & $\begin{array}{l}\text { Perspective [aerial - } \\
\text { terrestrial] } \\
\end{array}$ & \\
\hline & Focal length & Notes & & \\
\hline \multicolumn{5}{|c|}{ At the office: } \\
\hline \multirow{3}{*}{ 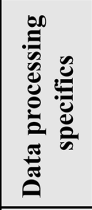 } & SfM tool & \multirow{5}{*}{ 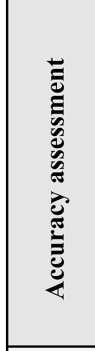 } & Registration residual & \\
\hline & $\begin{array}{l}\text { GCP integration } \\
\text { [1-/2-staged] }\end{array}$ & & \begin{tabular}{|l|} 
Reference type \\
[lidar, RTK pts, ... \\
\end{tabular} & \\
\hline & Output data type & & Reference error & \\
\hline \multirow{3}{*}{ 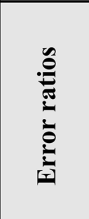 } & Relative error & & $\begin{array}{l}\text { Error measure }[\mathrm{M} 3 \mathrm{C} 2, \\
\text { raster difference, ...] }\end{array}$ & \\
\hline & \begin{tabular}{|l|}
$\begin{array}{l}\text { Reference } \\
\text { superiority }\end{array}$ \\
\end{tabular} & & \begin{tabular}{|l|} 
Statistical value \\
{$[$ RMSE, SD, ...] } \\
\end{tabular} & \\
\hline & $\begin{array}{l}\text { Theoretical error } \\
\text { ratio }\end{array}$ & Notes & & \\
\hline
\end{tabular}

Figure 6. Data acquisition and error assessment protocol for SfM photogrammetry, independent of individual study design.

ies during the next decade; perspectives include efforts in cross-disciplinarity, process automation, data and code sharing, real-time data acquisition and processing, unlocking the archives, etc., as follows.

\subsection{Cross-disciplinarity}

A great potential relies on adapting three-dimensional methods originally developed for the treatment of 3-D lidar data to investigate natural phenomena through SfM photogrammetry techniques. Applications on 3-D point cloud treatment dating back to the last decade will soon be integrated into SfM photogrammetry post-processing; examples include geomorphological investigations in high-mountain areas (Milan et al., 2007), geological mapping (Buckley et al., 2008; Franceschi et al., 2009), soil erosion studies (Eltner and Baumgart, 2015), investigation of fluvial systems (Heritage and Hetherington, 2007; Cavalli et al., 2008; Brasington et al., 2012), and mass wasting phenomena (Lim et al., 2005; Oppikofer et al., 2009; Abellán et al., 2010).
Some other data treatment techniques that have been developed during the last decade and that will be adapted and enriched by the growing SfM photogrammetry community include automatic lithological segmentation according to the intensity signature (Humair et al., 2015), integration of ground-based lidar with thermal/hyperspectral imaging for lithological discrimination (Kääb, 2008; Hartzell et al., 2014), extraction of the structural settings on a given outcrop (Jaboyedoff et al., 2007; Sturzenegger and Stead, 2009; Gigli and Casagli, 2011; Riquelme et al., 2014) and the automatic extraction of geological patterns such as surface roughness (Poropat, 2009) and discontinuity spacing/persistence/waviness (Fekete et al., 2010; Khoshelham et al., 2011; Pollyea and Fairley, 2011). Concerning 4-D data treatment for investigating changes on natural slope, some lessons learned may be adapted from the two- and threedimensional tracking of mass movements (Teza et al., 2007; Monserrat and Crosetto, 2008), investigation of progressive failures (Royan et al., 2015; Kromer et al., 2015), and from 
the usage of mobile systems (Lato et al., 2009; Michoud et al., 2015).

\subsection{Data and code sharing}

Open data in geomorphometric studies using point clouds are also needed. The development of open-source software for handling huge 3-D data sets such as CloudCompare (Girardeau-Montaut, 2015) has considerably boosted geomorphometric studies using 3-D point clouds due to providing facile processing of such memory-intense data. Nevertheless, apart from the above-mentioned case, sharing the source code or the RAW data of specific applications for investigating earth surface processes is still not well established in our discipline. A series of freely available databases exist for lidar data sets (www.openTopography.org, www.rockbench. org, http://3d-landslide.com/). However, to the knowledge of the authors, there is no specific GitHub cluster or website dedicated to the maintaining and development of open-access software in geosciences.

\subsection{Unlocking the archive}

The appraisal of digital photography and the exponential increase in data storage capabilities have enabled the existence of the massive archive of optical images around the world. Accessing such quantity of information could provide unexpected opportunities for the four-dimensional research of geomorphological processes using SfM photogrammetry workflows. Except for some open repositories (e.g. Flickr, Google Street View) the possibility to access the massive optical data is still scarce. In addition, accessing such databases may become a challenging task due to data interchangeability issues. A considerable effort may be necessary for creating such a database with homogeneous data formats and descriptors (type of phenomenon, temporal resolution, pixel size, accuracy, distance to object, existence of GCPs, etc.) during the coming years.

A first valuable approach to use data from online imagery was presented by Martin-Brualla et al. (2015), who pave the way for further research in a new field of 3-D surface analysis (i.e. time lapse). Other possible applications might unlock archives of historical airborne, helicopter-based or terrestrial imagery, ranging from the estimation of coastal retreat rates to the observation of the evolution of natural hazards to the monitoring of glacier fronts, and further.

\subsection{Real-time data acquisition}

Rapid developments in automation (soft- and hardware wise) allow for in situ data acquisition and its immediate transfer to processing and analysing institutions. Thus, extreme events are recognisable during their occurrence and authorities or rescue teams can be informed in real time. In this context SfM photogrammetry could help to detect and quantify rapid volume changes of, for example, glacier fronts, pro-glacial lakes, rock failures and ephemeral rivers.

Furthermore, real-time crowd sourcing offers an entirely new dimension of data acquisition. Due to the high connectivity of the public through smartphones, various possibilities arise to share data (Johnson-Roberson et al., 2015). An already implemented example is real-time traffic information. Jackson and Magro (2015) name further options. Crowdsourced imagery can largely expand possibilities to 3-D information.

\subsection{Time-lapse photography}

A limited frequency of data acquisition increases the likelihood of superimposition and coalescence of geomorphological processes (Abellán et al., 2014). Since time-lapse SfM photogrammetry data acquisition has remained so far unexplored, this topic is expected to be a great prospect during the coming years. To date, solely James and Robson (2014b) have demonstrated its potential by monitoring a lava flow at minute intervals for $37 \mathrm{~min}$. One reason why time-lapse SfM photogrammetry remains rather untouched in geosciences lies in the complex nature of producing continuous data sets.

Besides the need for an adequate research site (frequent morphodynamic activity), other aspects have to be taken into account: an automatic camera setup is required with self-contained energy supply (either via insolation or wind), adequate storage and appropriate choice of viewing angles onto the area of interest. Furthermore, cameras need to comprise sufficient image overlap and have to be synchronised. Ground control is required and an automatic pipeline for large data treatment should be developed.

New algorithms are necessary to deal with massive point cloud databases. Thus, innovative four-dimensional approaches have to be developed to take advantage of the information contained in real-time and/or time-lapse monitoring. Furthermore, handling huge databases is an important issue and although fully automatic techniques may not be necessary in some applications, a series of tedious and manual processes are still required for data treatment. Combining realtime and/or time-lapse data sets with climatic information can improve the modelling of geomorphological processes.

\subsection{Automatic UAV surveying}

Unmanned airborne vehicles already show a large degree of automation as they follow flight paths and acquire data autonomously. Human control is not required except for launching of a multicopter or fixed-wing system. Automatic landing is already provided by several systems. In the near future a fully automatic UAV installation could comprise the following: repeated survey of an area of interest, landing and charging at a base station, a data link for local storage or satellite-based data transfer, and a safety mechanism for preventing lift-off during inappropriate weather conditions. 
However, a large limitation for such a realisation lies in legal restrictions, because national authorities commonly request that visual contact to the UAV be maintained in case of failure. However, in remote areas installation of an automatic system could already be allowed by regulation authorities.

\subsection{Direct geo-referencing}

The use of GCPs is very time-consuming in the current SfM workflow. At first, a great deal of field efforts are needed to install and measure the GCPs during data acquisition. Afterwards, more time and labour are required during postprocessing in order to identify the GCPs in the images, although some progress is being made regarding to automatic GCP identification, e.g. by the exploitation of templates (Chen et al., 2000). The efficiency of geo-referencing can be increased significantly by applying direct geo-referencing. Thus, the location and position of the camera is measured in real time and synchronised to the image capture by an onboard GPS receiver and an IMU (inertial measurement unit) recording camera tilts. This applies to UAV systems as well as terrestrial data acquisition, e.g. by smartphones (Masiero et al., 2014). Exploiting direct geo-referencing can reduce usage of GCPs to a minimum or even replace it, which has already been demonstrated by Nolan et al. (2015), who generated DEMs with spatial extents of up to $40 \mathrm{~km}^{2}$ and a geolocation accuracy of $\pm 30 \mathrm{~cm}$.

The technique can be very advantageous when it comes to monitoring areas with great spatial extents or inaccessible research sites. However, further development is necessary, thereby focusing on lightweight but precise GPS receivers and IMU systems, on UAVs due to their limited payload, and on hand-held devices due to their feasibility (e.g. Eling et al., 2015).

\section{Conclusions}

This review has shown the versatility and flexibility of the recently established method SfM photogrammetry. Due to its beneficial qualities, a wide community of geoscientists starts to implement 3-D reconstruction based on images within a variety of studies. To summarise the publications, there are no considerable disadvantages mentioned (e.g. accuracywise) compared to other methods that cannot be counteracted by placement of GCPs, camera calibration or a high number of images. Frontiers in geomorphometry have been expanded once more, as limits of other surveying techniques such as restricted mobility, isolated area of application and high costs are overcome by SfM photogrammetry. Its major advantages lie in easy-to-handle and cost-efficient digital cameras as well as non-commercial software solutions.

SfM photogrammetry is already becoming an essential tool for digital surface mapping. It is employable in a fully automatic manner, but individual adjustments can be conducted to account for each specific case study constraint and accuracy requirement in regard to the intended application. Due to the possibility of different degrees of process interaction, non-experts can utilise the method depending on their discretion.

While research of the last years has mainly focused on testing the applicability of SfM photogrammetry in various geoscientific applications, recent studies have tried to pave the way for future usages and develop new tools, setups or algorithms. Performance analysis has revealed the suitability of SfM photogrammetry at a large range of scales in regard to case-study-specific accuracy necessities. However, different factors influencing final DEM quality still need to be addressed. This should be performed under strict experimental (laboratory) designs because complex morphologies, typical in earth surface observations, impede accuracy assessment due to missing superior reference. Thus, independent references and GCPs are still needed in SfM photogrammetry for reliable estimation of the quality of each 3-D reconstructed surface.

Fast and straightforward generation of DEMs using freely available tools produces new challenges. The exploitation of the entire information of the SfM photogrammetry output (3$\mathrm{D}$ point cloud or mesh instead of 2.5-D raster) will become a significant challenge in future studies of high-resolution topography (Passalacqua et al., 2015), which will need to be extended to even 4-D when investigating the evolution along time. Thus, comprehensive end-user software in particular needs further progress in these aspects. 


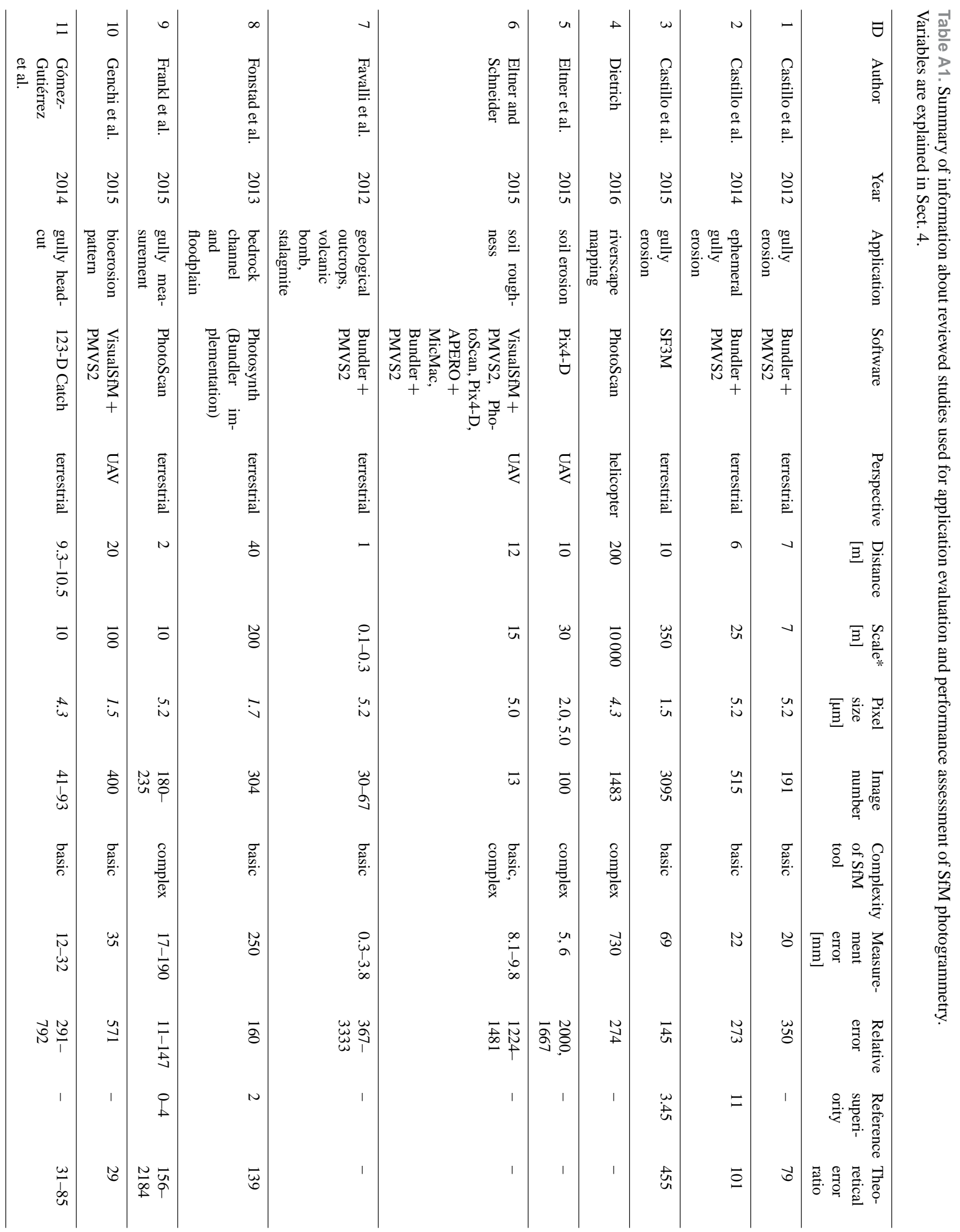




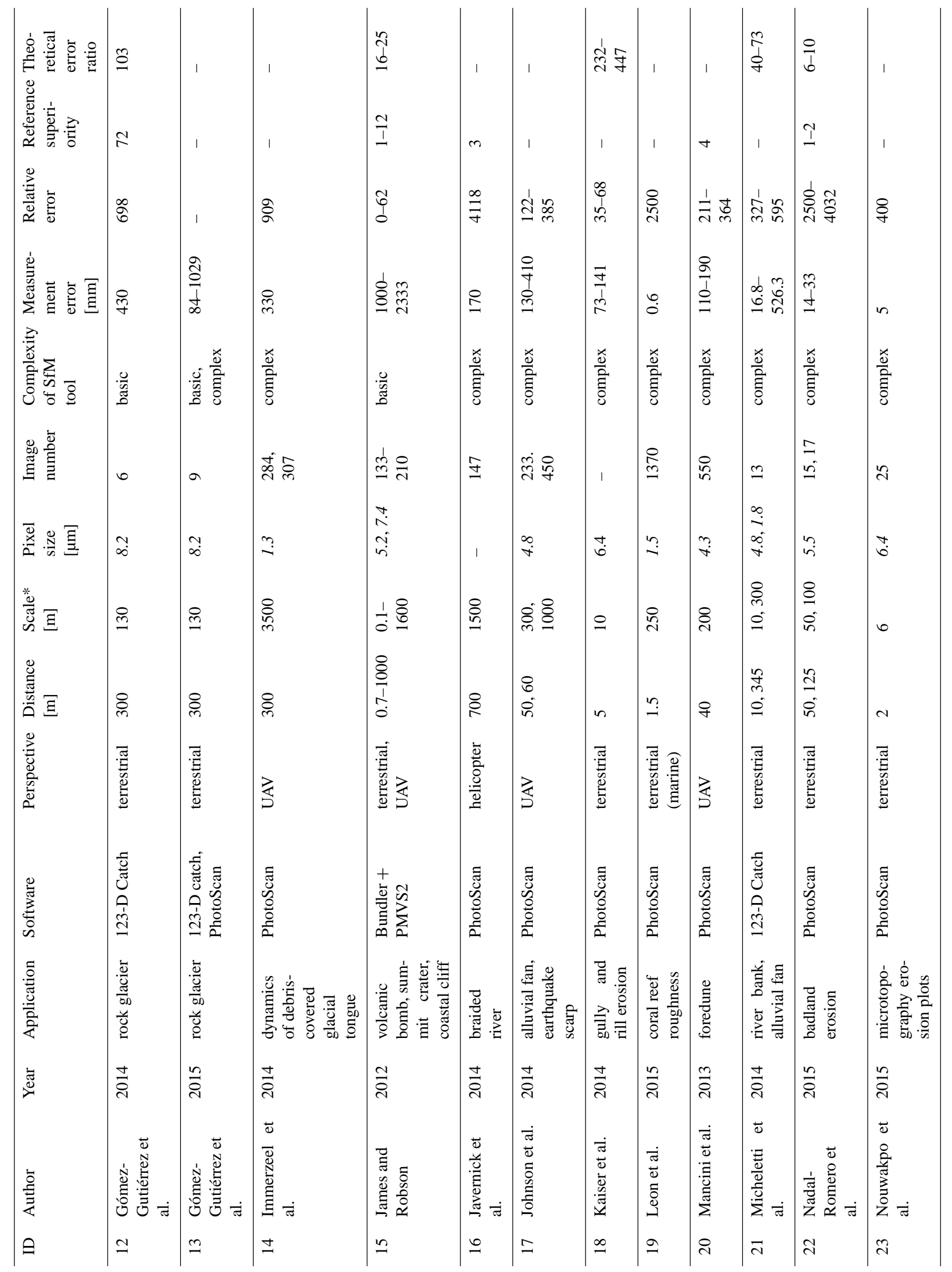




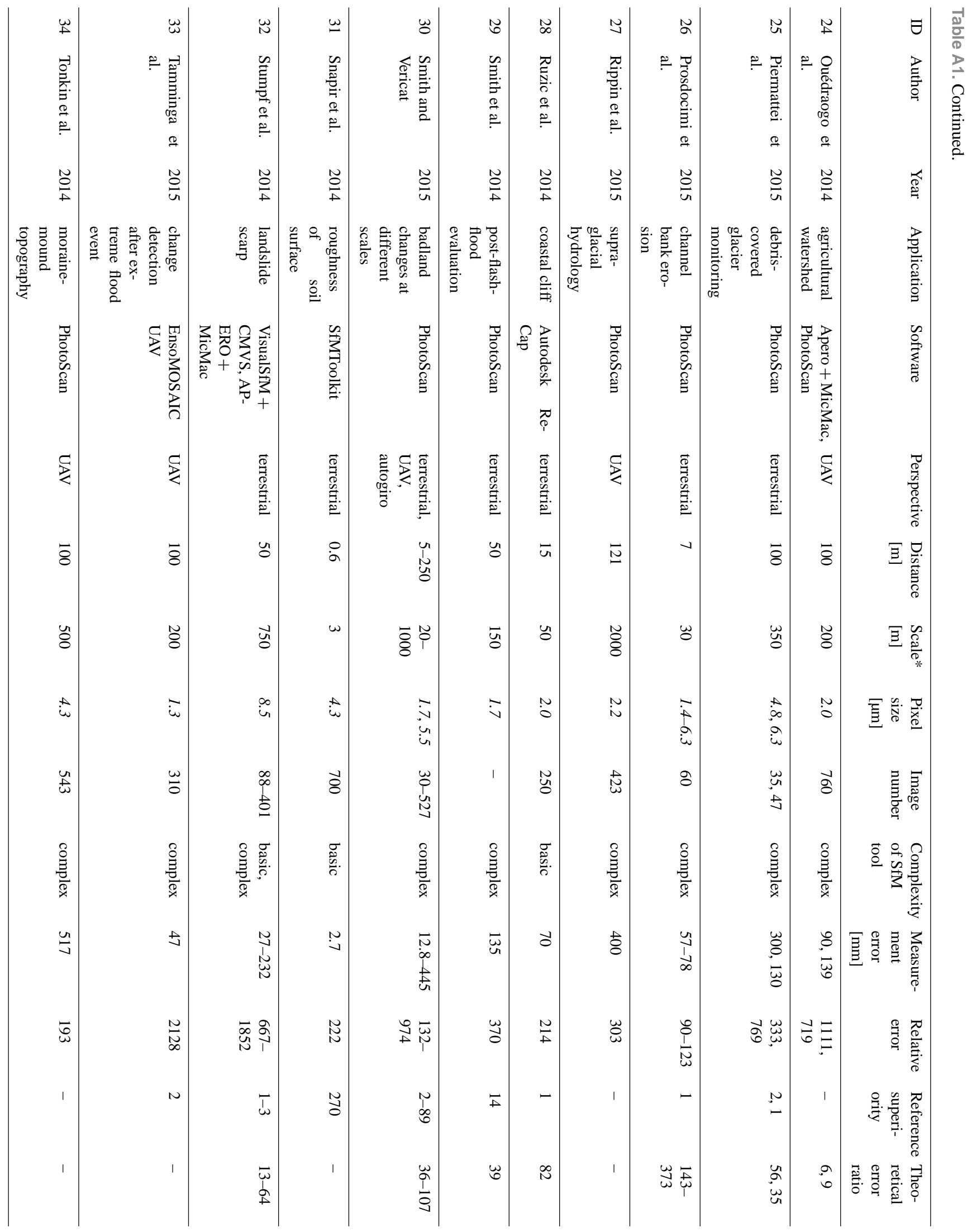




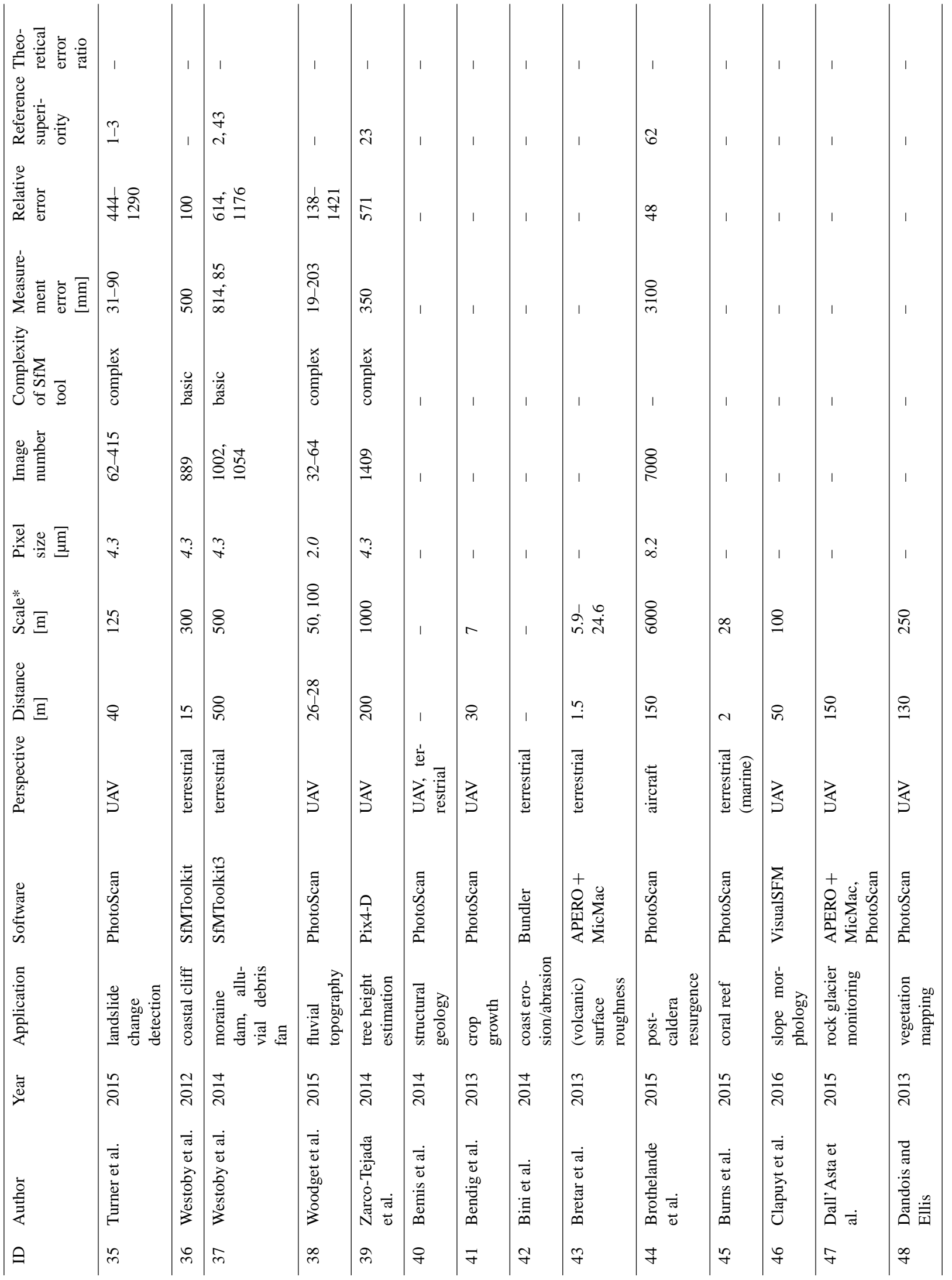




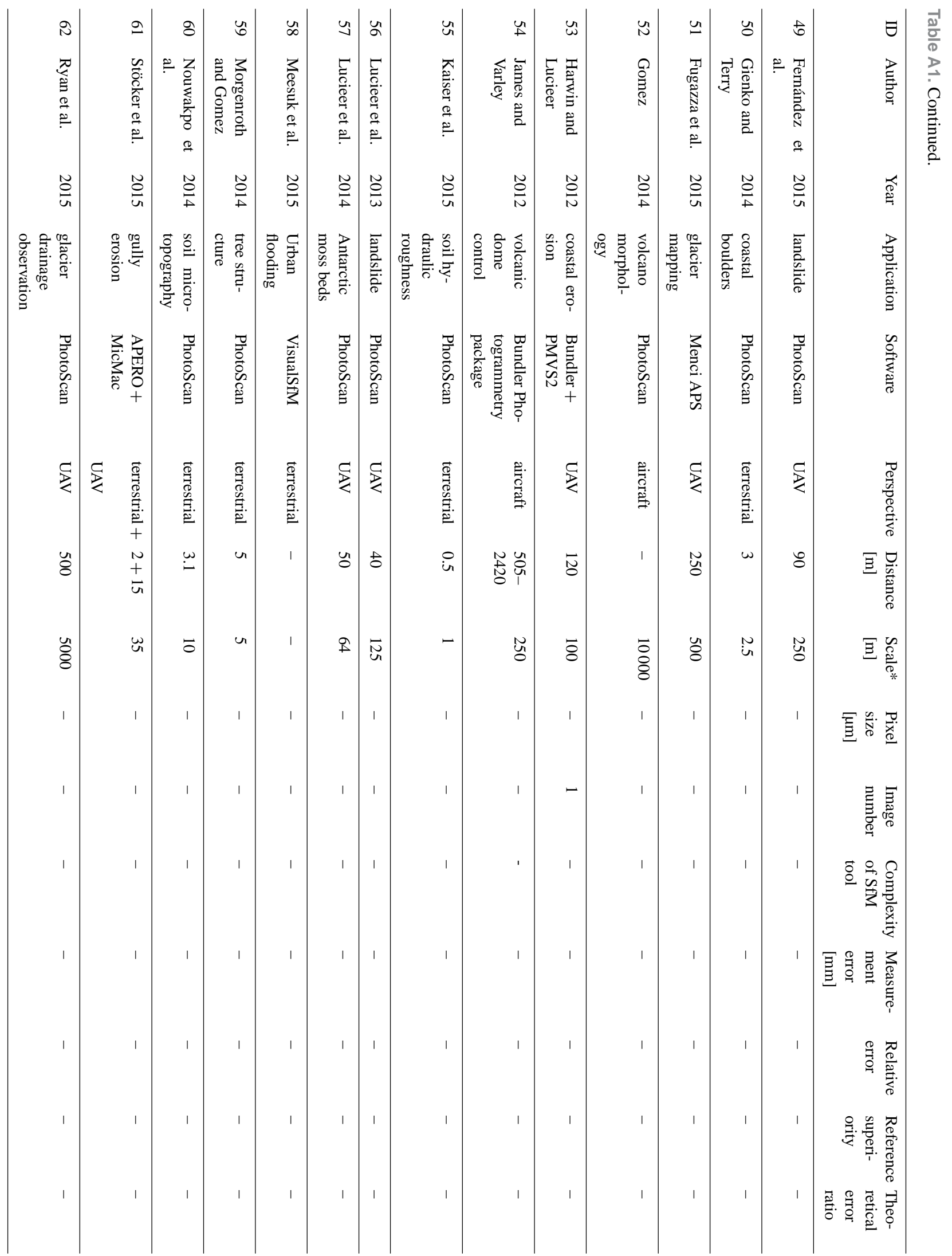




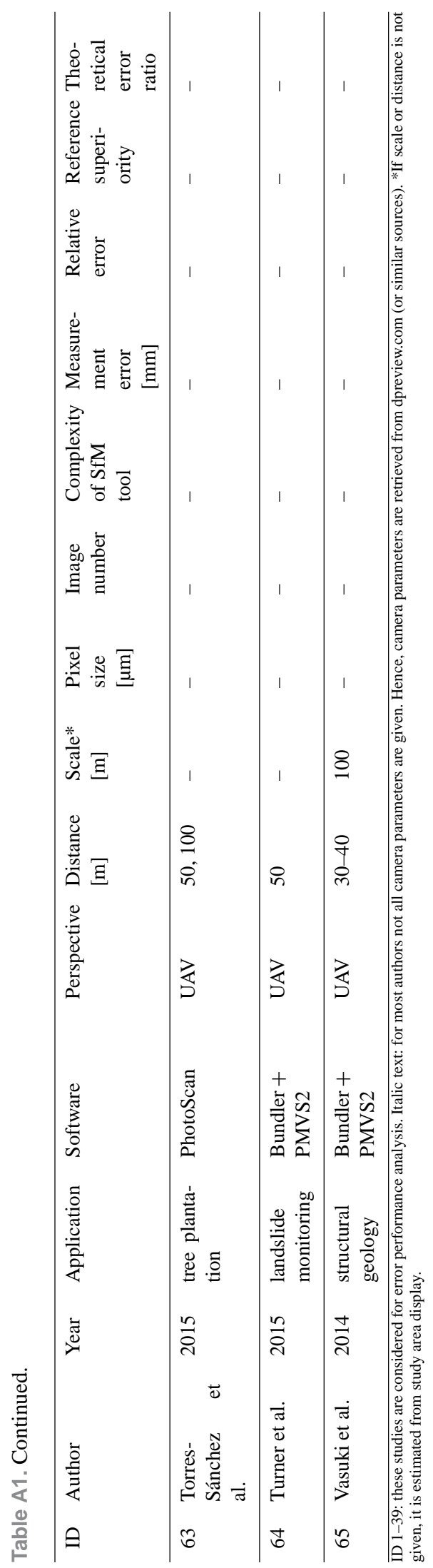


Acknowledgements. A. Eltner, A. Kaiser and F. Neugirg are funded by the German Research Foundation (DFG) (MA 2504/151, HA5740/3-1, SCHM1373/8-1). A. Abellán acknowledges support by the Risk Analysis group (Univ. Lausanne) and the UPC (RockRisk research project BIA2013-42582-P).

We would like to thank an anonymous referee and Matt Westoby for their remarks, which significantly improved the manuscript.

Edited by: G. Sofia

\section{References}

Abellán, A.: www.3D-LANDSLIDE.com, available at: http:// 3d-landslide.com/, last access: May 2016.

Abellán, A., Jaboyedoff, M., Oppikofer, T., and Vilaplana, J. M.: Detection of millimetric deformation using a terrestrial laser scanner: experiment and application to a rockfall event, Nat. Hazards Earth Syst. Sci., 9, 365-372, doi:10.5194/nhess-9-3652009, 2009.

Abellán, A., Calvet, J., Vilaplana, J. M., and Blanchard, J.: Detection and spatial prediction of rockfalls by means of terrestrial laser scanner monitoring, Geomorphology, 119, 162-171, doi:10.1016/j.geomorph.2010.03.016, 2010.

Abellán, A., Oppikofer, T., Jaboyedoff, M., Rosser, N. J., Lim, M., and Lato, M. J.: Terrestrial laser scanning of rock slope instabilities, Earth Surf. Proc. Land., 39, 80-97, doi:10.1002/esp.3493, 2014.

Ai, M., Hu, Q., Li, J., Wang, M., Yuan, H., and Wang, S.: A Robust Photogrammetric Processing Method of Low-Altitude UAV Images, Remote Sensing, 7, 2302-2333, doi:10.3390/rs70302302, 2015.

Astre, H.: SfMtoolkit, available at: http://www.visual-experiments. com/demos/sfmtoolkit/, last access: November 2015.

Bemis, S. P., Micklethwaite, S., Turner, D., James, M. R., Akciz, S., Thiele, S. T., and Bangash, H. A.: Ground-based and UAV-Based photogrammetry: A multi-scale, high- resolution mapping tool for structural geology and paleoseismology, J. Struct. Geol., 69, 163-178, doi:10.1016/j.jsg.2014.10.007, 2014.

Bendig, J., Bolten, A., and Bareth, G.: UAV-based Imaging for Multi-Temporal, very high Resolution Crop Surface Models to monitor Crop Growth Variability, Photogramm. Fernerkun., 6, 551-562, doi:10.1127/1432-8364/2013/0200, 2013.

Bini, M., Isola, I., Pappalardo, M., Ribolini, A., Favalli, M., Ragaini, L., and Zanchetta, G.: Abrasive notches along the Atlantic Patagonian coast and their potential use as sea level markers: the case of Puerto Deseado (Santa Cruz, Argentina), Earth Surf. Proc. Land., 39, 1550-1558, doi:10.1002/esp.3612, 2014.

Bracken, L. J., Turnbull, L., Wainwright, J., and Bogaart, P.: State of Science Sediment connectivity: a framework for understanding sediment transfer at multiple scales, Earth Surf. Proc. Land., 40, 177-188, doi:10.1002/esp.3635, 2015.

Brasington, J., Vericat, D., and Rychkov, I.: Modeling river bed morphology, roughness, and surface sedimentology using high resolution terrestrial laser scanning, Water Resour. Res., 48, W11519, doi:10.1029/2012WR012223, 2012.

Bretar, F., Arab-Sedze, M., Champion, J., Pierrot-Deseilligny, M., Heggy, E., and Jacquemoud, S.: An advanced photogrammetric method to measure surface roughness: Application to volcanic terrains in the Piton de la Fournaise, Reunion Island, Remote Sens. Environ., 135, 1-11, doi:10.1016/j.rse.2013.03.026, 2013. Brothelande, E., Lénat, J.-F., Normier, A., Bacri, C., Peltier, A., Paris, R., Kelfoun, K., Merle, O., Finizola, A., and Garaebiti, E.: Insights into the evolution of the Yenkahe resurgent dome (Siwi caldera, Tanna Island, Vanuatu) inferred from aerial high-resolution photogrammetry, J. Volcanol. Geoth. Res., doi:10.1016/j.jvolgeores.2015.04.006, 2015.

Brown, M. Z., Burschka, D., and Hager, G. D.: Advances in Computational Stereo, IEEE T. Pattern Anal., 25, 993-1008, 2003.

Buckley, S., Howell, J., Enge, H., and Kurz, T.: Terrestrial laser scanning in geology: data acquisition, processing and accuracy considerations, J. Geol. Soc. London, 165, 625-638, 2008.

Burns, J. H. R., Delparte, D., Gates, R. D., and Takabayashi, M.: Integrating structure-from-motion photogrammetry with geospatial software as a novel technique for quantifying 3D ecological characteristics of coral reefs, PeerJ, 3, e1077, doi:10.7717/peerj.1077, 2015.

Castillo, C., Pérez, R., James, M. R., Quinton, J. N., Taguas, E. V., and Gómez, J. A.: Comparing the Accuracy of Several Field Methods for Measuring Gully Erosion, Soil Sci. Soc. Am. J., 76, 1319-1332, doi:10.2136/sssaj2011.0390, 2012.

Castillo, C., Taguas, E. V., Zarco-Tejada, P., James, M. R., and Gómez, J. A.: The normalized topographic method: an automated procedure for gully mapping using GIS, Earth Surf. Proc. Land., 39, 2002-2015, doi:10.1002/esp.3595, 2014.

Castillo, C., James, M. R., Redel-Macías, M. D., Pérez, R., and Gómez, J. A.: SF3M software: 3-D photo-reconstruction for nonexpert users and its application to a gully network, SOIL, 1, 583594, doi:10.5194/soil-1-583-2015, 2015.

Cavalli, M., Tarolli, P., Marchi, L., and Fontana, G. D.: The effectiveness of airborne LiDAR data in the recognition of channel-bed morphology, Catena, 73, 249-260, doi:10.1016/j.catena.2007.11.001, 2008.

Chandler, J.: Effective application of automated digital photogrammetry for geomorphological research, Earth Surf. Proc. Land., 24, 51-63, 1999.

Chen, L. C., Lo, C. Y., Liu, C. L., and Chen, A. J.: Orientation modelling by matching image templates of a GCP database, Proc. 21st ACRS, 21, 2000.

Cignoni, P., Callieri, M., Corsini, M., Dellepiane, M., Ganovelli, F., and Ranzuglia, G.: MeshLab: an Open-Source Mesh Processing Tool, in: Eurographics Italian Chapter Conference, Salerno, Italy, 129-136, 2008.

Clapuyt, F., Vanacker, V., and Van Oost, K.: Reproducibility of UAV-based earth topography reconstructions based on Structure-from-Motion algorithms, Geomorphology, 260, 4-15, doi:10.1016/j.geomorph.2015.05.011, 2016.

Collier, P.: The impact on topographic mapping of developments in land and air survey: 1900-1939, Cartogr. Geogr. Inform., 29, 155-174, 2002.

Dall'Asta, E., Delaloye, R., Diotri, F., Forlani, G., Fornari, Morro di Cella, U. M., Pogliotti, P., Roncella, R., and Santise, M.: Use of UAS in a High Mountain Landscape: the Case of Gran Sommetta Rock Glacier (AO). ISPRS - Int. Arch. Photogramm., XL-3/W3, 391-397, 2015.

Dandois, J. P. and Ellis, E. C.: High spatial resolution threedimensional mapping of vegetation spectral dynamics us- 
ing computer vision, Remote Sens. Environ., 136, 259-276, doi:10.1016/j.rse.2013.04.005, 2013.

Díaz-Varela, R., de la Rosa, R., León, L., and Zarco-Tejada, P.: High-Resolution Airborne UAV Imagery to Assess Olive Tree Crown Parameters Using 3-D Photo Reconstruction: Application in Breeding Trials, Remote Sensing, 7, 4213-4232. doi:10.3390/rs70404213, 2015.

Dietrich, J. T.: Riverscape Mapping with Helicopter-Based Structure-From-Motion Photogrammetry, Geomorphology, 252, 144-157, doi:10.1016/j.geomorph.2015.05.008, 2016.

Doyle, F.: The Historical Development of Analytical Photogrammetry, Photogramm. Eng., 15, 259-265, 1964.

Ducher, G.: Photogrammetry - The largest operational application of remote sensing, Photogrammetria, 41, 72-82, 1987.

East, A. E., Pess, G. R., Bountry, J. A., Magirl, C. S., Ritchie, A. C., Logan, J. B., Randle, T. J., Mastin, M. C., Minear, J. T., Duda, J. J., Liermann, M. C., McHenry, M. L., Beechie, T. J., and Shafroth, P. B.: Reprint of: Large-scale dam removal on the Elwha River, Washington, USA: River channel and floodplain geomorphic change, Geomorphology, 246, 687-708, doi:10.1016/j.geomorph.2015.04.027, 2015.

Eling, C., Wieland, M., Hess, C., Klingbeil, L., and Kuhlmann, H.: Development and evaluation of a UAV based mapping system for remote sensing and surveying applications, ISPRS - Int. Arch. Photogramm., XL-1/W4, 233-239, 2015.

Eltner, A. and Baumgart, P.: Accuracy constraints of terrestrial Lidar data for soil erosion measurement: Application to a Mediterranean field plot, Geomorphology, 245, 243-254, doi:10.1016/j.geomorph.2015.06.008, 2015.

Eltner, A. and Schneider, D.: Analysis of Different Methods for 3-D Reconstruction of Natural Surfaces from Parallel-Axes UAV Images, Photogramm. Rec., 30, 279-299, doi:10.1111/phor.12115, 2015.

Eltner, A., Mulsow, C., and Maas, H.: Quantitative Measurement of Soil Erosion from Tls and Uav Data, ISPRS - Int. Arch. Photogramm., XL-1/W2, 119-124, 2013.

Eltner, A., Baumgart, P., Maas, H.-G., and Faust, D.: Multitemporal UAV data for automatic measurement of rill and interrill erosion on loess soil, Earth Surf. Proc. Land., 40, 741-755, doi:10.1002/esp.3673, 2015.

Favalli, M., Fornaciai, A., Isola, I., Tarquini, S., and Nannipieri, L.: Multiview 3-D reconstruction in geosciences, Comput. Geosci., 44, 168-176, doi:10.1016/j.cageo.2011.09.012, 2012.

Fekete, S., Diederichs, M., and Lato, M.: Geotechnical and operational applications for 3-dimensional laser scanning in drill and blast tunnels, Tunn. Undergr. Sp. Tech., 25, 614-628, doi:10.1016/j.tust.2010.04.008, 2010.

Fernández, T., Pérez, J. L., Cardenal, F. J., López, A., Gómez, J. M., Colomo, C., Delgado, J., and Sánchez, M.: Use of a Light UAV and Photogrammetric Techniques To Study the Evolution of a Landslide in Jaén (Southern Spain), ISPRS - Int. Arch. Photogramm. Rem. Sens., XL-3/W3, 241-248, doi:10.5194/isprsarchives-XL-3-W3-241-2015, 2015.

Fonstad, M. A., Dietrich, J. T., Courville, B. C., Jensen, J. L., and Carbonneau, P. E.: Topographic structure from motion: a new development in photogrammetric measurement, Earth Surf. Proc. Land., 38, 421-430, doi:10.1002/esp.3366, 2013.

Frahm, J.-M., Pollefeys, M., Lazebnik, S., Gallup, D., Clipp, B., Raguram, R., Wu, C., Zach, C., and Johnson, T.:
Fast robust large-scale mapping from video and internet photo collections, ISPRS J. Photogramm., 65, 538-549, doi:10.1016/j.isprsjprs.2010.08.009, 2010.

Franceschi, M., Teza, G., Preto, N., Pesci, A., Galgaro, A., and Girardi, S.: Discrimination between marls and limestones using intensity data from terrestrial laser scanner, ISPRS J. Photogramm., 64, 522-528, doi:10.1016/j.isprsjprs.2009.03.003, 2009.

Francioni, M., Salvini, R., Stead, D., Giovannini, R., Riccucci, S., Vanneschi, C., and Gullì, D.: An integrated remote sensingGIS approach for the analysis of an open pit in the Carrara marble district, Italy: Slope stability assessment through kinematic and numerical methods, Comp. Geot., 67, 46-63, doi:10.1016/j.compgeo.2015.02.009, 2015.

Frank1, A., Stal, C., Abraha, A., Nyssen, J., Rieke-Zapp, D., De Wulf, A., and Poesen, J.: Detailed recording of gully morphology in 3-D through image-based modelling PhotoScan Digital Elevation Model (DEM) Soil pipes Structure from M otion-Multi View Stereo (SfM-MVS) Volume calculation, Catena, 127, 92101, doi:10.1016/j.catena.2014.12.016, 2015.

Fugazza, D., Senese, A., Azzoni, R. S., Smiraglia, C., Cernuschi, M., Severi, D. D., and Guglielmina, A.: High-resolution mapping of glacier surface features. The UAV survey of the Forni glacier (Stelvio National Park, Italy), Geogr. Fis. Din. Quat., 38, 25-33, doi:10.4461/GFDQ.2015.38.03, 2015.

Furukawa, Y. and Ponce, J.: Accurate, dense, and robust multiview stereopsis, IEEE T. Pattern Anal., 83, 1362-1376, doi:10.1109/TPAMI.2009.161, 2010.

Furukawa, Y., Curless, B., Seitz, S. M., and Szeliski, R.: Towards Internet-scale multi-view stereo, in: IEEE Conference on Computer Vision and Pattern Recognition, San Francisco, CA, USA, 1434-1441, doi:10.1109/CVPR.2010.5539802, 2010.

Genchi, S. A., Vitale, A. J., Perillo, G. M. E., and Delrieux, C. A.: Structure-from-Motion Approach for Characterization of Bioerosion Patterns Using UAV Imagery, Sensors, 15, 3593-3609, doi:10.3390/s150203593, 2015.

Gienko, G. A. and Terry, J. P.: Three-dimensional modeling of coastal boulders using multi-view image measurements, Earth Surf. Proc. Land., 39, 853-864, doi:10.1002/esp.3485, 2014.

Gigli, G. and Casagli, N.: Semi-automatic extraction of rock mass structural data from high resolution LIDAR point clouds, Int. J. Rock Mech. Min., 48, 187-198, doi:10.1016/j.ijrmms.2010.11.009, 2011.

Girardeau-Montaut, D.: CloudCompare (version 2.x; GPL software), EDF RandD, Telecom ParisTech, available at: http://www. cloudcompare.org/, last access: March 2015.

Gomez, C.: Digital photogrammetry and GIS-based analysis of the bio-geomorphological evolution of Sakurajima Volcano, diachronic analysis from 1947 to 2006. J. Volcanol. Geoth., 280, 1-13, 2014.

Gomez, C., Hayakawa, Y., and Obanawa, H.: A study of Japanese landscapes using structure from motion derived DSMs and DEMs based on historical aerial photographs: New opportu- nities for vegetation monitoring and diachronic geomorphology, Geomorphology, 242, 11-20, doi:10.1016/j.geomorph.2015.02.021, 2015.

Gómez-Gutiérrez, Á., de Sanjosé-Blasco, J. J., de MatíasBejarano, J., and Berenguer-Sempere, F.: Comparing Two PhotoReconstruction Methods to Produce High Density Point Clouds and DEMs in the Corral del Veleta Rock Glacier (Sierra Nevada, 
Spain), Remote Sensing, 6, 5407-5427, doi:10.3390/rs6065407, 2014a.

Gómez-Gutiérrez, Á., Schnabel, S., Berenguer-Sempere, F., Lavado-Contador, F., and Rubio-Delgado, J.: Using 3-D photoreconstruction methods to estimate gully headcut erosion, Catena, 120, 91-101, doi:10.1016/j.catena.2014.04.004, 2014b.

Gómez-Gutiérrez, Á., de Sanjosé-Blasco, J., Lozano-Parra, J., Berenguer-Sempere, F., and de Matías-Bejarano, J.: Does HDR Pre-Processing Improve the Accuracy of 3-D Models Obtained by Means of two Conventional SfM-MVS Software Packages? The Case of the Corral del Veleta Rock Glacier, Remote Sensing, 7, 10269-10294, doi:10.3390/rs70810269, 2015.

Gruen, A.: Development and status of image matching in photogrammetry, Photogramm. Rec., 27, 36-57, doi:10.1111/j.14779730.2011.00671.x, 2012.

Harrap, R., and Lato, M.: Rockbench - Sharing Geospatial Reference Datasets, available at: http://geol.queensu.ca/faculty/harrap/ RockBench, last access: May 2016.

Hartzell, P., Glennie, C., Biber, K., and Khan, S.: Application of multispectral LiDAR to automated virtual outcrop geology, ISPRS J. Photogramm., 88, 147-155. doi:10.1016/j.isprsjprs.2013.12.004, 2014.

Harwin, S. and Lucieer, A.: Assessing the Accuracy of Georeferenced Point Clouds Produced via Multi-View Stereopsis from Unmanned Aerial Vehicle (UAV) Imagery, Remote Sensing, 4, 1573-1599, doi:10.3390/rs4061573, 2012.

Heritage, G. and Hetherington, D.: Towards a protocol for laser scanning in fluvial geomorphology, Earth Surf. Proc. Land., 32, 66-74, doi:10.1002/esp.1375, 2007.

Hirschmüller, H.: Semi-Global Matching - Motivation, Developments and Applications, Photogrammetric Week, 11, 173-184, 2011

Humair, F., Abellan, A., Carrea, D., Matasci, B., Epard, J.-L., and Jaboyedoff, M.: Geological layers detection and characterisation using high resolution 3-D point clouds: example of a box-fold in the Swiss Jura Mountains, Eur. J. Rem. Sens., 48, 541-568, doi:10.5721/EuJRS20154831, 2015.

Immerzeel, W. W., Kraaijenbrink, A., Shea, J. M., Shrestha, A. B., Pellicciotti, F., Bierkens, M. F. P., and De Jong, S. M.: Highresolution monitoring of Himalayan glacier dynamics using unmanned aerial vehicles, Remote Sens. Environ., 150, 93-103, doi:10.1016/j.rse.2014.04.025, 2014.

Jaboyedoff, M., Metzger, R., Oppikofer, T., Couture, R., Derron, M.-H., Locat, J., and Turmel, D.: New insight techniques to analyze rock-slope relief using DEM and 3-D- imaging cloud points: COLTOP-3-D software, in: Rock Mechanics: Meeting Society's Challenges and Demands, edited by: Eberhardt, E., Stead, D., and Morrison, T., 1st edn., Taylor and Francis, London, UK, 6168, 2007.

Jaboyedoff, M., Oppikofer, T., Abellán, A., Derron, M.-H., Loye, A., Metzger, R., and Pedrazzini, A.: Use of LIDAR in landslide investigations: a review, Nat. Hazards, 61, 5-28, doi:10.1007/s11069-010-9634-2, 2012.

Jackson, M. and Magro, G.: Real-time crowd-sourcing, data and modelling, in: IAIA15 Conference Proceedings, 20-23 April 2015, Florence, Italy, 2015.

James, M. R. and Robson, S.: Straightforward reconstruction of 3-D surfaces and topography with a camera: Accuracy and geoscience application, J. Geophys. Res., 117, F03017, doi:10.1029/2011JF002289, 2012.

James, M. R. and Varley, N.: Identification of structural controls in an active lava dome with high resolution DEMs: Volcán de Colima, Mexico, Geophys. Res. Lett., 39, L22303, doi:10.1029/2012GL054245, 2012.

James, M. R. and Robson, S.: Mitigating systematic error in topographic models derived from UAV and ground-based image networks, Earth Surf. Proc. Land., 39, 1413-1420, doi:10.1002/esp.3609, 2014a.

James, M. R. and Robson, S.: Sequential digital elevation models of active lava flows from ground-based stereo time-lapse imagery, ISPRS J. Photogramm. Rem. Sens., 97, 160-170, doi:10.1016/j.isprsjprs.2014.08.011, 2014b.

Javernick, L., Brasington, J., and Caruso, B.: Modeling the topography of shallow braided rivers using Structure-fromMotion photogrammetry, Geomorphology, 213, 166-182, doi:10.1016/j.geomorph.2014.01.006, 2014

Johnson, K., Nissen, E., Saripalli, S., Arrowsmith, J. R., Mcgarey, P., Scharer, K., Williams, P., and Blisniuk, K.: Rapid mapping of ultrafine fault zone topography with structure from motion, Geosphere, 10, 969-986, doi:10.1130/GES01017.1, 2014.

Johnson-Roberson, M., Bryson, M., Douillard, B., Pizarro, O., and Williams, S. B.: Discovering salient regions on 3-D phototextured maps: Crowdsourcing interaction data from multitouch smartphones and tablets, Comput. Vis. Image Und., 131, 28-41, doi:10.1016/j.cviu.2014.07.006, 2015.

Kääb, A.: Glacier Volume Changes Using ASTER Satellite Stereo and ICESat GLAS Laser Altimetry. A Test Study on Edgeøya, Eastern Svalbard, IEEE T. Geosci. Remote, 46, 2823-2830, doi:10.1109/TGRS.2008.2000627, 2008.

Kääb, A., Girod, L., and Berthling, I.: Surface kinematics of periglacial sorted circles using structure-from-motion technology, The Cryosphere, 8, 1041-1056, doi:10.5194/tc-8-10412014, 2014.

Kaiser, A., Neugirg, F., Rock, G., Müller, C., Haas, F., Ries, J., and Schmidt, J.: Small-Scale Surface Reconstruction and Volume Calculation of Soil Erosion in Complex Moroccan Gully Morphology Using Structure from Motion, Remote Sensing, 6, 7050-7080, doi:10.3390/rs6087050, 2014.

Kaiser, A., Neugirg, F., Haas, F., Schmidt, J., Becht, M., and Schindewolf, M.: Determination of hydrological roughness by means of close range remote sensing, SOIL, 1, 613-620, doi:10.5194/soil-1-613-2015, 2015.

Khoshelham, K., Altundag, D., Ngan-Tillard, D., and Menenti, M.: Influence of range measurement noise on roughness characterization of rock surfaces using terrestrial laser scanning, Int. J. Rock Mech. Min., 48, 1215-1223, doi:10.1016/j.ijrmms.2011.09.007, 2011.

Kraus, K.: Photogrammetry: Geometry from Images and Laser Scans, 2nd edition, De Gruyter, Berlin, Germany, 459 pp., 2007.

Kromer, R., Abellán, A., Hutchinson, D., Lato, M., Edwards, T., and Jaboyedoff, M.: A 4-D Filtering and Calibration Technique for Small-Scale Point Cloud Change Detection with a Terrestrial Laser Scanner, Remote Sensing, 13029-13052, doi:10.3390/rs71013029, 2015.

Lague, D., Brodu, N., and Leroux, J.: Accurate 3-D comparison of complex topography with terrestrial laser scanner: Application to 
the Rangitikei canyon (N-Z), ISPRS J. Photogramm., 82, 10-26, doi:10.1016/j.isprsjprs.2013.04.009, 2013.

Laussedat, A.: La métrophotographie, Bibliothèque Photographique, Gauthier-Villars, Paris, 55 pp., 1899.

Lato, M., Hutchinson, J., Diederichs, M., Ball, D., and Harrap, R.: Engineering monitoring of rockfall hazards along transportation corridors: using mobile terrestrial LiDAR, Nat. Hazards Earth Syst. Sci., 9, 935-946, doi:10.5194/nhess-9-935-2009, 2009.

Leon, J. X., Roelfsema, C. M., Saunders, M. I., and Phinn, S. R.: Measuring coral reef terrain roughness using "Structure-fromMotion" close-range photogrammetry, Geomorphology, 242, 21-28, doi:10.1016/j.geomorph.2015.01.030, 2015.

Lim, M., Petley, D. N., Rosser, N. J., Allison, R. J., Long, A. J., and Pybus, D.: Combined digital photogrammetry and time-of-flight laser scanning for monitoring cliff evolution, Photogramm. Rec., 20, 109-129, 2005.

Lowe, D. G.: Object recognition from local scale-invariant features, The Proceedings of the 7th IEEE International Conference on Computer Vision, 2, 1150-1157, 1999.

Lucieer, A., de Jong, S., and Turner, D.: Mapping landslide displacements using Structure from Motion (SfM) and image correlation of multi-temporal UAV photography, Prog. Phys. Geog., 38, 1-20, doi:10.1177/0309133313515293, 2013.

Lucieer, A., Turner, D., King, D. H., and Robinson, S. A.: Using an unmanned aerial vehicle (UAV) to capture micro-topography of antarctic moss beds, Int. J. Appl. Earth Obs., 27, 53-62, doi:10.1016/j.jag.2013.05.011, 2014.

Luhmann, T., Robson, S., Kyle, S., and Boehm, J.: Close-Range Photogrammetry and 3-D Imaging, 2nd edition, De Gruyter, Berlin, Germany, 683 pp., 2014.

Mancini, F., Dubbini, M., Gattelli, M., Stecchi, F., Fabbri, S., and Gabbianelli, G.: Using Unmanned Aerial Vehicles (UAV) for High-Resolution Reconstruction of Topography: The Structure from Motion Approach on Coastal Environments, Remote Sensing, 5, 6880-6898, doi:10.3390/rs5126880, 2013.

Martin-Brualla, R., Gallup, D., and Seitz, S. M.: Time-lapse Mining from Internet Photos. in: IEEE International Conference on Computer Vision (ICCV), 13-16 December 2015.

Masiero, A., Guarnieri, A., Vettore, A., and Pirotti, F.: An ISVDbased Euclidian structure from motion for smartphones, Int. Arch. Photogramm. Rem. Sens., XL-5, 401-406, 2014.

Meesuk, V., Vojinovic, Z., Mynett, A. E., and Abdullah, A. F.: Urban flood modelling combining top-view LiDAR data with ground-view SfM observations, Adv. Water Res., 75, 105-117, doi:10.1016/j.advwatres.2014.11.008, 2015.

Micheletti, N., Chandler, J. H., and Lane, S. N.: Investigating the geomorphological potential of freely available and accessible structure-from-motion photogrammetry using a smartphone, Earth Surf. Proc. Land., 40, 473-486, doi:10.1002/esp.3648, 2014.

Micheletti, N., Chandler, J. H., and Lane, S. N.: Structure from Motion (SfM) Photogrammetry (Chap. 2, Sect. 2.2), in: Geomorphological Techniques, British Society of Geomorphology, edited by: Cook, S. J., Clarke L. E., and Nield, J. M., London, UK, 2015.

Michoud, C., Carrea, D., Costa, S., Derron, M.-H., Jaboyedoff, M., Delacourt, C., Maquaire, O., Letortu, P., and Davidson, R.: Landslide detection and monitoring capability of boat-based mo- bile laser scanning along Dieppe coastal cliffs, Normandy, Landslides, 12, 403-418, 2015.

Mikhail, E., Bethel, J., and McGlone, J.: Introduction to Modern Photogrammetry, John Wiley and Sons, Inc., New York, USA, 479 pp., 2001.

Milan, D. J., Heritage, G. L., and Hetherington, D.: Assessment of erosion and deposition volumes and channel change Application of a 3-D laser scanner in the assessment of erosion and deposition volumes and channel change in a proglacial river, Earth Surf. Proc. Land., 32, 1657-1674, doi:10.1002/esp.1592, 2007.

Monserrat, O. and Crosetto, M.: Deformation measurement using terrestrial laser scanning data and least squares 3D surface matching, ISPRS J. Photogramm., 63, 142-154, doi:10.1016/j.isprsjprs.2007.07.008, 2008.

Morgenroth, J. and Gomez, C.: Assessment of tree structure using a 3-D image analysis technique - A proof of concept, Urban For. Urban Green., 13, 198-203, doi:10.1016/j.ufug.2013.10.005, 2014

Nadal-Romero, E., Revuelto, J., Errea, P., and López-Moreno, J. I.: The application of terrestrial laser scanner and SfM photogrammetry in measuring erosion and deposition processes in two opposite slopes in a humid badlands area (central Spanish Pyrenees), SOIL, 1, 561-573, doi:10.5194/soil-1-561-2015, 2015.

Nolan, M., Larsen, C., and Sturm, M.: Mapping snow depth from manned aircraft on landscape scales at centimeter resolution using structure-from-motion photogrammetry, The Cryosphere, 9, 1445-1463, doi:10.5194/tc-9-1445-2015, 2015.

Nouwakpo, S. K., James, M. R., Weltz, M. A., Huang, C.-H., Chagas, I., and Lima, L.: Evaluation of structure from motion for soil microtopography measurement, Photogramm. Rec., 29, 297-316, doi:10.1111/phor.12072, 2014.

Nouwakpo, S. K., Weltz, M. A., and McGwire, K.: Assessing the performance of Structure-from-Motion photogrammetry and terrestrial lidar for reconstructing soil surface microtopography of naturally vegetated plots, Earth Surf. Proc. Land., 41, 308-322, doi:10.1002/esp.3787, 2015.

OpenTopography Facility: OpenTopography - HighResolution Topography Data and Tools, available at: http://www.opentopography.org, last access: May 2016.

Oppikofer, T., Jaboyedoff, M., Blikra, L., Derron, M.-H., and Metzger, R.: Characterization and monitoring of the Åknes rockslide using terrestrial laser scanning, Nat. Hazards Earth Syst. Sci., 9, 1003-1019, doi:10.5194/nhess-9-1003-2009, 2009.

Ouédraogo, M. M., Degré, A., Debouche, C., and Lisein, J.: The evaluation of unmanned aerial system-based photogrammetry and terrestrial laser scanning to generate DEMs of agricultural watersheds, Geomorphology, 214, 339-355, doi:10.1016/j.geomorph.2014.02.016, 2014.

Passalacqua, P., Belmont, P., Staley, D. M., Simley, J. D., Arrowsmith, J. R., Bode, C. A., Crosby, C., DeLong, S. B., Glenn, N. F., Kelly, S. A., Lague, D., Sangireddy, H., Schaffrath, K., Tarboton, D. G., Wasklewicz, T., and Wheaton, J. M.: Analyzing high resolution topography for advancing the understanding of mass and energy transfer through landscapes: A review, Earth-Sci. Rev., 148, 174-193, doi:10.1016/j.earscirev.2015.05.012, 2015.

Pears, N., Liu, Y., and Bunting, P.: 3-D Imaging, Analysis and Applications, Springer, London, UK, 499 pp., 2012.

Piermattei, L., Carturan, L., and Guarnieri, A.: Use of terrestrial photogrammetry based on structure from motion for mass bal- 
ance estimation of a small glacier in the Italian Alps, Earth Surf. Proc. Land., 40, 1791-1802, doi:10.1002/esp.3756, 2015.

Pierrot-Deseilligny, M. and Clery, I.: APERO, an open source bundle adjustment software for automatic calibration and orientation of set of images, Intern. Arch. Photogramm., 38-5(W16), 269276, 2011.

Pierrot-Deseilligny, M. and Clery, I.: Some possible protocols of acquisition for the optimal use of the "Apero" open source software in automatic orientation and calibration, EuroCow 2012, Barcelona, Spain, 10 pp., 2012.

Pike, R. J., Evans, I. S., and Hengl, T.: Geomorphometry: a Brief Guide, in: Geomorphometry: Concepts, Software, Applications, edited by: Hengl, T. and Reuter, H. I., Dev. Soil Sci., 33, 1-28, 2008.

Pollyea, R. and Fairley, J.: Estimating surface roughness of terrestrial laser scan data using orthogonal distance regression, Geology, 39, 623-626, doi:10.1130/G32078.1, 2011.

Poropat, G.: Measurement of Surface Roughness of Rock Discontinuities, in: Proc. of the 3rd CANUS Rock Mechanics Symposium, 9-14 May 2009, Toronto, Canada, 2009.

Prosdocimi, M., Calligaro, S., Sofia, G., Dalla Fontana, G., and Tarolli, P.: Bank erosion in agricultural drainage networks: new challenges from Structure-from-Motion photogrammetry for post-event analysis, Earth Surf. Proc. Land., 40, 1891-1906, doi:10.1002/esp.3767, 2015.

Remondino, F., Spera, M. G., Nocerino, E., Menna, F., and Nex, F.: State of the art in high density image matching, Photogramm. Rec., 29, 144-166, doi:10.1111/phor.12063, 2014.

Rippin, D. M., Pomfret, A., and King, N.: High resolution mapping of supraglacial drainage pathways reveals link between micro-channel drainage density, surface roughness and surface reflectance, Earth Surf. Proc. Land., 40, 1279-1290, doi:10.1002/esp.3719, 2015. Riquelme, A., Abellán, A., Tomás, R., and Jaboyedoff, M.: A new approach for semi-automatic rock mass joints recognition from 3D point clouds, Comput. Geosci., 68, 38-52, doi:10.1016/j.cageo.2014.03.014, 2014.

Royan, M., Abellan, A., and Vilaplana, J.: Progressive failure leading to the 3 December 2013 rockfall at Puigcercós scarp (Catalonia, Spain), Landslides, 12, 585-595, 2015.

Ružić, I., Marovic, I., Benac, C., and Ilic, S.: Coastal cliff geometry derived from structure-from-motion photogrammetry at Stara Baka, Krk Island, Croatia, Geo-Mar. Lett., 34, 555-565, doi:10.1007/s00367-014-0380-4, 2014.

Ryan, J. C., Hubbard, A. L., Box, J. E., Todd, J., Christoffersen, P., Carr, J. R., Holt, T. O., and Snooke, N.: UAV photogrammetry and structure from motion to assess calving dynamics at Store Glacier, a large outlet draining the Greenland ice sheet, The Cryosphere, 9, 1-11, doi:10.5194/tc-9-1-2015, 2015.

Sanz-Ablanedo, E., Rodríguez-Pérez, J. R., Armesto, J., and Taboada, M. F. Á.: Geometric stability and lens decentering in compact digital cameras, Sensors, 10, 1553-1572 doi:10.3390/s100301553, 2010.

Schaffalitzky, F. and Zisserman, A.: Multi-view matching for unordered image sets, or "How do I organize my holiday snaps?", Computer Vision - ECCV 2002, 2350, 414-431, doi:10.1007/3540-47969-4, 2002.

Shortis, M. R., Bellman, C. J., Robson, S., Johnston, G. J., and Johnson, G. W.: Stability of Zoom and Fixed Lenses used with Dig- ital SLR Cameras, Intern. Arch. Photogramm., Remote Sensing, XXXVI, 285-290, 2006.

Siebert, S. and Teizer, J.: Mobile 3-D mapping for surveying earthwork projects using an Unmanned Aerial Vehicle (UAV) system, Automat. Constr., 41, 1-14, doi:10.1016/j.autcon.2014.01.004, 2014.

Smith, M. W. and Vericat, D.: From experimental plots to experimental landscapes: topography, erosion and deposition in subhumid badlands from Structure-from-Motion photogrammetry, Earth Surf. Proc. Land., 40, 1656-1671, doi:10.1002/esp.3747, 2015.

Smith, M. W., Carrivick, J. L., Hooke, J., and Kirkby, M. J.: Reconstructing flash flood magnitudes using "Structure-fromMotion": A rapid assessment tool, J. Hydrol., 519, 1914-1927, doi:10.1016/j.jhydrol.2014.09.078, 2014.

Smith, M. W., Carrivick, J. L., and Quincey, D. J.: Structure from motion photogrammetry in physical geography, Prog. Phys. Geog., 1-29, doi:10.1177/0309133315615805, 2015.

Snapir, B., Hobbs, S., and Waine, T. W.: Roughness measurements over an agricultural soil surface with Structure from Motion, ISPRS J. Photogramm., 96, 210-223, doi:10.1016/j.isprsjprs.2014.07.010, 2014.

Snavely, N., Seitz, S. M., and Szeliski, R.: Photo Tourism?: Exploring Photo Collections in 3-D, ACM T. Graphic., 25, 835-846, 2006.

Snavely, N., Seitz, S. M., and Szeliski, R.: Modeling the World from Internet Photo Collections, Intern. J. Comput. Vis., 80, 189-210, doi:10.1007/s11263-007-0107-3, 2008.

Stöcker, C., Eltner, A., and Karrasch, P.: Measuring gullies by synergetic application of UAV and close range photogrammetry - A case study from Andalusia, Spain, Catena, 132, 1-11, doi:10.1016/j.catena.2015.04.004, 2015.

Stumpf, A., Malet, J.-P., Allemand, P., Pierrot-Deseilligny, M., and Skupinski, G.: Ground-based multi-view photogrammetry for the monitoring of landslide deformation and erosion, Geomorphology, 231, 130-145, doi:10.1016/j.geomorph.2014.10.039, 2014.

Sturzenegger, M., and Stead, D.: Close-range terrestrial digital photogrammetry and terrestrial laser scanning for discontinuity characterization on rock cuts, Eng. Geol., 106, 163182, doi:10.1016/j.enggeo.2009.03.004, 2009. Tamminga, A. D., Eaton, B. C., and Hugenholtz, C. H.: UAS-based remote sensing of Wuvial change following an extreme Wood event, Earth Surf. Proc. Land., 40, 1464-1476, doi:10.1002/esp.3728, 2015.

Teza, G., Galgaro, A., Zaltron, N., and Genevois, R.: Terrestrial laser scanner to detect landslide displacement fields: a new approach, Int. J. Remote S., 28, 3425-3446, doi:10.1080/01431160601024234, 2007.

Thomsen, L. M., Baartman, J. E. M., Barneveld, R. J., Starkloff, T., and Stolte, J.: Soil surface roughness: comparing old and new measuring methods and application in a soil erosion model, SOIL, 1, 399-410, doi:10.5194/soil-1-399-2015, 2015.

Tonkin, T. N., Midgley, N. G., Graham, D. J., and Labadz, J. C.: The potential of small unmanned aircraft systems and structure-frommotion for topographic surveys: A test of emerging integrated approaches at Cwm Idwal, North Wales, Geomorphology, 226, 35-43, doi:10.1016/j.geomorph.2014.07.021, 2014.

Torres-Sánchez, J., López-Granados, F., Serrano, N., Arquero, O., and Peña, J. M.: High-Throughput 3-D Monitoring of Agricultural-Tree Plantations with Unmanned Aerial 
Vehicle (UAV) Technology, PLOS One, 10, e0130479, doi:10.1371/journal.pone.0130479, 2015.

Triggs, B., McLauchlan, P., Hartley, R., and Fitzgibbon, A.: Bundle Adjustment - A Modern Synthesis, in: Vision Algorithms: Theory and Practice, edited by: Triggs, B., Zisserman, A., and Szeliski, R., Springer, Berlin, Germany, LNCS, 1883, 298-372, 2000.

Turner, D., Lucieer, A., and de Jong, S.: Time Series Analysis of Landslide Dynamics Using an Unmanned Aerial Vehicle (UAV), Remote Sensing, 7, 1736-1757, doi:10.3390/rs70201736, 2015.

Ullman, S.: The interpretation of structure from motion, P. R. Soc. B, 203, 405-426, 1979.

Vasuki, Y., Holden, E. J., Kovesi, P., and Micklethwaite, S.: Semiautomatic mapping of geological Structures using UAV-based photogrammetric data: An image analysis approach, Comput. Geosci., 69, 22-32, doi:10.1016/j.cageo.2014.04.012, 2014.

Westoby, M. J., Brasington, J., Glasser, N. F., Hambrey, M. J., and Reynolds, J. M.: "Structure-from-Motion" photogrammetry: A low-cost, effective tool for geoscience applications, Geomorphology, 179, 300-314, doi:10.1016/j.geomorph.2012.08.021, 2012.

Westoby, M. J., Glasser, N. F., Hambrey, M. J., Brasington, J., Reynolds, J. M., and Hassan, M. A. A. M.: Reconstructing historic glacial lakeoutburst floods through numerical modelling and geomorphological assessment: Extreme events in the Himalaya, Earth Surf. Proc. Land., 39, 1675-1692, doi:10.1002/esp.3617, 2014.
Woodget, A. S., Carbonneau, P. E., Visser, F., and Maddock, I. P.: Quantifying submerged fluvial topography using hyperspatial resolution UAS imagery and structure from motion photogrammetry, Earth Surf. Proc. Land., 40, 47-64, doi:10.1002/esp.3613, 2015.

Wu, C.: Towards linear-time incremental structure from motion, in: International Conference on 3-D Vision - 3-DV, Seattle, WA USA, 127-134, 2013.

Wu, C.: Critical configurations for radial distortion self-calibration, in: IEEE Conference on Computer Vision and Pattern Recognition (CVPR), 25-32, doi:10.1109/CVPR.2014.11, 2014.

Zarco-Tejada, P. J., Diaz-Varela, R., Angileri, V., and Loudjani, P.: Tree height quantification using very high resolution imagery acquired from an unmanned aerial vehicle (UAV) and automatic 3-D photo-reconstruction methods, Eur. J. Agron., 55, 89-99, doi:10.1016/j.eja.2014.01.004, 2014. 